\title{
DYNAMIC IMPACTS OF COMMODITY FLOW DISRUPTIONS IN INLAND WATERWAY NETWORKS
}

Raghav Pant, Kash Barker, Thomas L. Landers

Raghav Pant, Ph.D.

Environmental Change Institute

Centre for the Environment

University of Oxford

Kash Barker, Ph.D.

Assistant Professor

School of Industrial and Systems Engineering

University of Oklahoma

Thomas L. Landers, Ph.D., P.E.

Dean, College of Engineering, and AT\&T Chair

Professor, School of Industrial and Systems Engineering

University of Oklahoma

Corresponding author:

Kash Barker

202 West Boyd Street, Room 124

Norman, Oklahoma 73019

Phone 405-325-3721

Fax 405-325-7555

kashbarker@ou.edu 


\begin{abstract}
Freight and passenger transport in the US is projected to increase substantially by 2035 making a strong case for greater usage of the inland waterway barge transport. Inland waterway networks constitute an important component of the US multi-modal transport infrastructure spanning 25,000 miles of navigable routes across 38 states. Risk-based preparedness planning for inland waterway networks requires a means to assess the interdependent impacts associated with closures to inland waterway infrastructure. This study proposes a dynamic framework to assess multi-regional, multi-industry losses due to disruptions on the waterway networks, including ports and waterway links. We investigate simulation-driven disruptive scenarios, such as dock closures, that affect daily commerce across the waterway network and integrate with a dynamic interdependency model to quantify the effect of disruptions on industry inoperability across multiple regions and multiple industries. We implement our framework with a data-driven case study of the operations at the Port of Catoosa on the McClellan-Kerr Arkansas River branch of the Mississippi River Navigation System. Resulting dock-specific, industry-specific, and regionspecific insights can guide preparedness decision making.
\end{abstract}

\title{
KEYWORDS
}

Dynamic inoperability, multi-regional economics, inland waterway network 


\section{INTRODUCTION AND MOTIVATION}

Modern economies rely on lifeline infrastructures for delivery of goods and services. To maintain steady economic activity it is important to understand disruption impacts on infrastructure functionality, and subsequent recovery towards the normal operations. Infrastructure disruptions impact large-scale economies because they cascade beyond the region of impact [Santos 2006]. Government policy makers and industry decision makers have a need for understanding disruption impacts to facilitate distribution of resources where they will be most useful in ensuring return to normal production levels, whether for the economy as a whole or for individual supply chains.

Macroeconomic damage impact assessment and recovery decision making are very relevant for the transportation infrastructure, listed amongst the US critical infrastructure and key resources [DHS 2009]. Transportation networks such as highways, railways, and waterways are vital for maintaining the connectivity of commodity flow networks. As many industries depend on these transportation systems, economic impacts of their disruption can become widespread due to the spatial and temporal distributions of commodity flows. Even without large-scale disruptions, there already exist economic losses in highway and railway networks under current operating conditions. The Federal Highway Administration (FHWA) has calculated that delays caused by highway bottlenecks "cost the trucking industry alone more than $\$ 8$ billion a year" [GAO 2008]. The FHWA estimated in 2000 that trucks were responsible for $\$ 10.9$ billion (in 2010 dollars) in congestion costs to other highway users [GAO 2011]. Such losses are projected to increase over time because: (i) the US domestic freight tonnages are expected to grow by $50 \%$ over the next 20 years [NCFRP 2010], resulting in an increase to as much as $73 \%$ by 2035 relative to 2008 levels [USDOT 2009], and (ii) national highway systems are forecasted to experience up to $40 \%$ peak congestion by 2035, creating slowdowns and stop-and-go conditions on significant stretches of highway [USDOT 2009]. Railways are also projected to face significant congestion over time due to increased demand on Class I railroads [AAR 2007]. Under current working conditions, service breakdowns for railroads are estimated to increase from 108 miles in 2007 to 16,000 miles in 2035 [AAR 2007]. For domestic freight transport in the US inland waterway networks present a viable alternative for resolving some of these congestion problems because far fewer barges are required to transport to the same amount of freight compared to truck or rail [TTI 2007].

Recognizing the need to reduce road and rail congestions, the US Maritime Administration, a division of the US Department of Transportation, has called for an investment in inland waterways for general freight movement [USDOT 2011]. The increased use of the 25,000 miles of commercially navigable waterways for freight transport will likely lead to reduced congestions on US highways, as well as reduced risk of accidents relative to highway and rail transport and reduced air pollution emissions. Transportation by barge is often cheaper than the alternatives of rail and truck, and there are many products that are too large for other methods of transport. Around 38 states depend on inland waterways to move as much as 630 million tons annually in the last decade [US Army Corps of Engineers 2010], currently a distant third compared to roadway and rail.

The potential for growing containerized freight transport has led to an increase in the need to address freight container transport disruptions due to extreme climate impacts or malevolent 
man-made attacks. As the most recent Report Card for America's Infrastructure gave inland waterway infrastructure a D- [ASCE 2013], inland ports are particularly susceptible to natural climate impacts and accidental failures. While there have been a number of studies addressing port security [Trbojevic and Carr 2000, Talley and Lun 2012] and the impacts of disruptive events at coastal ports [Chang 2000, Yip 2008], there is very little literature addressing such problems at inland ports. Most work is devoted to optimizing port operations [Kia et al. 2002, Dang et al. 2012, Francesco et al. 2013]

Further, research focusing on economic impact analyses of disruptions to transportation systems has primarily been devoted to highway and railway transport systems [Sohn et al. 2004, Gordon et al. 2004, Ham et al. 2005a,b], with inland waterway networks receiving little research attention. Pant et al. [2011] and MacKenzie et al. [2012a] conducted studies of multi-regional economic loss estimations due to inland waterway port disruptions, with further modeling work needed. This paper contributes to the interdependent impact assessment literature for inland waterway disruptions by providing a framework to more effectively model the spatial and temporal extent of inland waterway disruptions. This study provides a means to valuate dynamic macroeconomic recovery at a multi-regional scale following inland port and waterway disruptions, extending the work of Pant et al. [2012]. We focus on economic losses from disruptions in exports and imports of commodities on inland ports and waterways. Such disruptions create supply and demand shortages for the industries using facilities along the waterways. The multiplier effects due to interdependence further magnify economic losses for entire regional economies. Ultimately, the framework developed here will inform the decision making process for protecting against and preparing for inland waterway disruptions.

The interdependent impact assessment undertaken in this research relies on appropriate datadriven models and simulation tools. We use a risk-based extension to the economic input-output model [Leontief 1966], which describes the interdependent relationship among industry and infrastructure sectors in meeting final (end user) demand. A dynamic multi-regional, multiindustry interdependency model [Lian and Haimes 2006, Crowther and Haimes 2010] describes the temporal nature of the onset of reduced productivity in a set of industry sectors, how inoperability then propagates to other interdependent industries, and then how productivity improves over time. In addition to showing the trajectory of inoperability for industry sectors, the dynamic interdependency model also allows for the calculation of economic loss associated with a disruption. Both forms of analysis can be used to identify critical industries that would benefit the most from investments in disaster prevention and recovery. To understand the spatial extent of inland waterways we use network commodity flow data provided by the US Army Corps of Engineers [2013], which also provides the basis for disruption modeling. Finally, the flow of commodities through a port (network node) can be subdivided into specific dock flows, allowing us to model dock-specific commodities that are transported on and off the barges into the network and thus better understand dock-specific disruptions.

Section 2 provides some methodological background of the construction of a dynamic multiregional, multi-industry model of disruptive impact, and introduces measures of disruption and resilience. Section 3 examines port and waterway models describing commodity flows and subsequently disruptions to those flows. In Section 4 the integration of Sections 2 and 3 is illustrated with a case study of the Port of Catoosa, an inland port in Tulsa, Oklahoma, on the 
McClellan-Kerr Arkansas River branch of the Mississippi River Navigation System. Concluding remarks follow in Section 5.

\section{Dynamic Model of Multi-Regional, Multi-Industry ImPaCt}

This section provides some of the methodological background to address the dynamic, multiregional nature of disruptions to transportation infrastructures and industry sectors. In the subsections that follow, we (i) explain the dynamic multi-regional interdependency model used here for quantifying the impacts of infrastructure disruptions, (ii) show how waterway disruptions are parameterized in the interdependency model, and (iii) discuss the ability of the dynamic model to describe the recovery characteristics of interdependent infrastructures and industries.

\subsection{Multi-Regional, Multi-Industry Inoperability}

The Leontief economic input-output model [1966] has been widely accepted as a useful model for analyzing the interdependent connections among industry sectors [Lave 1995, Isard et al. 1998, Miller and Blair 2009]. It assumes that for $n$ industries behaving under a static equilibrium, the total output of the $i$ th industry is distributed to all other industries (intermediate demand) and to final users (external demand). This equilibrium condition is described with $x_{i}=\sum_{j=1}^{n} z_{i j}+$ $c_{i}$, where $x_{i}$ is the output, $c_{i}$ is the external demand for industry $i$, and $z_{i j}$ describes the flow of commodities output from industry $i$ and used as input to production in industry $j$. The flow of commodities $z_{i j}$ is assumed to be proportional to the output of industry $j$, expressed as $z_{i j}=$ $a_{i j} x_{j}$. In vector form $(\mathbf{x}=\mathbf{A x}+\mathbf{c})$, total industry output $\mathbf{x}$ is produced to satisfy (i) intermediate sector demands (Ax) required by other industries for their production, and (ii) final exogenous demands (c) to meet consumer needs. $\mathbf{A}$ is an industry-by-industry matrix of interdependency coefficients. The extensive usage of input-output models is due, in part, to the availability of interdependency data (A matrix) describing the interconnected nature of infrastructures and industries in a number of countries [OECD 2011], including an extensive data collection effort by the US Bureau of Economic Analysis (BEA), which maintains input-output tables at different levels of aggregations [BEA 2011]. Appendix Table A1 explains the tabular structure of the input-output balances of economic sectors and Table A2 provides a list of 63 industries that typically represents the type of interdependent sectors being considered in a regional economic input-output model.

An extension of the economic input-output model of interest to this work is the Inoperability Input-Output Model (IIM) [Santos and Haimes 2004]. Instead of describing the supply-demand linkages among the interdependent industry sectors in terms of commodity flow dollars, the IIM illustrates how normalized production losses propagate through all interconnected industries. The IIM uses inoperability as an alternative metric for examining the effects of a disruption and has a similar form to the Leontief input-output model. The IIM is provided in Eq. (1), which describes the relationships among $n$ infrastructure and industry sectors, in terms of the $n \times n$ size matrix $\mathbf{A}^{\star}$ and vectors $\mathbf{q}$ and $\mathbf{c}^{\star}$ of length $n \times 1$.

$$
\mathbf{q}=\mathbf{A}^{\star} \mathbf{q}+\mathbf{c}^{\star} \Rightarrow \mathbf{q}=\left[\mathbf{I}-\mathbf{A}^{\star}\right]^{-1} \mathbf{c}^{\star}
$$


Vector $\mathbf{q}$ here is a vector of infrastructure and industry inoperabilities describing the extent to which ideal functionality is not realized following a disruptive event. Inoperability for sector $i$, defined in Eq. (2), represents the proportional reductions in production following output losses. Here as-planned total output is represented with $\hat{x}_{i}$ and degraded total output resulting from a disruption is represented with $\tilde{x}_{i}$. An inoperability of 0 suggests that an industry is operating at normal production levels, while an inoperability of 1 means that the industry is not producing.

$$
q_{i}=\left(\hat{x}_{i}-\tilde{x}_{i}\right) / \hat{x}_{i} \Leftrightarrow \mathbf{q}=[\operatorname{diag}(\hat{\mathbf{x}})]^{-1}(\hat{\mathbf{x}}-\tilde{\mathbf{x}})
$$

Normalized interdependency matrix $\mathbf{A}^{\star}$ is a modified version of the original $\mathbf{A}$ matrix describing the extent of economic interdependence among a set of infrastructure and industry sectors.

Shown in Eq. (3), the row elements of $\mathbf{A}^{\star}$ indicate the proportions of additional inoperability that are contributed by a column sector to the row sector.

$$
a_{i j}^{\star}=a_{i j}\left(\hat{x}_{j} / \hat{x}_{i}\right) \Leftrightarrow \mathbf{A}^{\star}=[\operatorname{diag}(\hat{\mathbf{x}})]^{-1} \mathbf{A}[\operatorname{diag}(\hat{\mathbf{x}})]
$$

Eq. (4) provides the calculation of $\mathbf{c}^{\star}$, a vector of normalized demand reduction. The elements of $\mathbf{c}^{\star}$ represent the difference in as-planned demand $\hat{c}_{i}$ and perturbed demand $\tilde{c}_{i}$ divided by asplanned production, quantifying the final demand reduction for sector $i$ as a proportion of total as-planned output.

$$
c_{i}^{\star}=\left(\hat{c}_{i}-\tilde{c}_{i}\right) / \hat{x}_{i} \Leftrightarrow \mathbf{c}^{\star}=[\operatorname{diag}(\hat{\mathbf{x}})]^{-1}(\hat{\mathbf{c}}-\tilde{\mathbf{c}})
$$

Economic losses can be calculated by multiplying each industry's production level by its inoperability level: for industry $i, Q_{i}=x_{i} q_{i}$, or for the entire economy of industries, $Q=\mathbf{x}^{T} \mathbf{q}$.

The multi-regional form of the IIM, describing how inoperability, or the lack of industry or infrastructure functionality, extends across multiple industries and multiple regions, is modeled with the MRIIM [Crowther and Haimes 2010] in Eqs. (5) and (6). Based on a multi-regional model by Isard et al. [1998], the MRIIM models an interconnected set of $n$ infrastructure and industry sectors in $p$ regions, expressing the equilibrium among sector outputs in each region and intermediary and final product consumptions. If $q_{i}^{r}$ is the inoperability experienced in industry $i$ in region $r$, then the multi-regional propagation of inoperability is expressed in Eq. (5), where $t_{i}^{\star r s}$ is the proportion of industry $i$ inoperability that disperses from region $r$ to region $s, a_{i j}^{\star s}$ is the proportion of industry $i$ inoperability propagated to industry $j$ after it comes from all sources in region $s$, and $c_{i}^{\star s}$ is the perturbation of demand for industry $i$ in region $s$. Eq. (6) expresses this relationship in matrix form.

$$
q_{i}^{r}=\sum_{s=1}^{p} \sum_{j=1}^{n} t_{i}^{\star r s} a_{i j}^{\star s} q_{j}^{s}+\sum_{s=1}^{p} t_{i}^{\star r s} c_{i}^{\star s}
$$




$$
\left[\begin{array}{c}
\mathbf{q}^{1} \\
\vdots \\
\mathbf{q}^{p}
\end{array}\right]=\left[\begin{array}{ccc}
\mathbf{T}^{\star 11} & \cdots & \mathbf{T}^{\star 1 p} \\
\vdots & \ddots & \vdots \\
\mathbf{T}^{\star p 1} & \cdots & \mathbf{T}^{\star p p}
\end{array}\right]\left[\begin{array}{ccc}
\mathbf{A}^{\star 1} & \cdots & \mathbf{0} \\
\vdots & \ddots & \vdots \\
\mathbf{0} & \cdots & \mathbf{A}^{\star p}
\end{array}\right]\left[\begin{array}{c}
\mathbf{q}^{1} \\
\vdots \\
\mathbf{q}^{p}
\end{array}\right]+\left[\begin{array}{ccc}
\mathbf{T}^{\star 11} & \cdots & \mathbf{T}^{\star 1} p \\
\vdots & \ddots & \vdots \\
\mathbf{T}^{\star p 1} & \cdots & \mathbf{T}^{\star p p}
\end{array}\right]\left[\begin{array}{c}
\mathbf{c}^{\star 1} \\
\vdots \\
\mathbf{c}^{\star p}
\end{array}\right]
$$

In Eq. (6), $\mathbf{T}^{\star r s}=\left[\operatorname{diag}\left(t_{i}^{\star r s}\right)\right], \forall i=\{1,2, \ldots, n\}$, is the trade coefficient matrix, an $n \times n$ matrix that represents the interdependence of infrastructures and industries between region $r$ and region $s$. Matrix $\mathbf{A}^{\star s}=\left[a_{i j}^{\star s}\right], \forall i, j=\{1,2, \ldots, n\}$ is an $n \times n$ regional industry-by-industry interdependency matrix for region $s$, that can be derived by regionalizing the traditional $\mathbf{A}$ matrix via the use of location quotients [Santos 2006]. Vector $\mathbf{q}^{s}=\left[q_{i}^{s}\right], \forall i=\{1,2, \ldots, n\}$ is the $n \times 1$ vector of inoperability in region $s$, while $\mathbf{c}^{\star s}=\left[c_{i}^{\star s}\right], \forall i=\{1,2, \ldots, n\}$ is the $n \times 1$ vector of demand perturbation experienced in region $s$. In addition to the BEA data that helps to parameterize $\mathbf{A}^{\star s}$, data from the Bureau of Transportation Statistics [2011] are available to construct the trade coefficient matrices, $\mathbf{T}^{\star r s}$, for different regions in the United States.

\subsection{Dynamic Extensions}

While the original IIM provides the state of industrial production at static equilibrium, the dynamic IIM [Lian and Haimes 2006] models the onset of a disruption, its interdependent effects, and its dissipation over time. Moreover, there are different time scales over which the actual disruptive events take place and both direct and multiplier economic effects are generated. The DIIM accounts for the recovery of industries, describing how long it takes the sectors to recover from a disruption as determined by pre-disruption preparedness activities and investments. This is a very useful attribute of the model, as recovery time may be a known variable that can be improved with the input of additional resources. The $n$-sector DIIM equation for the evolution of interdependent inoperability in discrete time-steps given by $0,1,2, \ldots, t-1$, $t, t+1, \ldots$ with time interval $\Delta t=1$ is expressed in Eq. (7). All parameters represent the same constructs as their static model counterparts, except that $\mathbf{q}(t)$ and $\mathbf{c}^{\star}(t)$ are inoperability and demand perturbation values specifically at time $t$, respectively. The matrix $\mathbf{K}$, referred to as the resilience coefficient matrix, represents a short-term behavior of sectors to invest in adjustments in changing outputs. $\mathbf{K}$ is a diagonal matrix whose diagonal elements $0 \leq k_{i i} \leq 1, \forall i=$ $\{1,2, \ldots, n\}$ represent the ability of each sector to attain stable responses to changes in production outputs and demands. The $[0,1]$ bounds ensure that the solution of Eq. (7) leads to mathematical and practical convergent solutions. Diagonal elements closer to 1 represent faster recovery, while values closer to 0 represent slower sector recovery.

$$
\mathbf{q}(t+1)=\mathbf{q}(t)+\mathbf{K}\left[\mathbf{A}^{\star} \mathbf{q}(t)+\mathbf{c}^{\star}(t)-\mathbf{q}(t)\right]
$$

We integrate the multi-regional inoperability model of Eq. (6) with the dynamic model, resulting in Eq. (8) [MacKenzie et al. 2012a], where $[\mathbf{q}(t)]$ and $\left[\mathbf{c}^{\star}(t)\right]$ are $n p \times 1$ temporal vectors for multi-regional sector inoperabilities and demand perturbations, respectively. Matrices $\left[\mathbf{T}^{\star}\right]$ and $\left[\mathbf{A}^{\star}\right]$ are the $n p \times n p$ interdependency matrices from Eq. (6) and [K] is an $n p \times n p$ multi-regional sector resilience diagonal matrix.

$$
[\mathbf{q}(t+1)]=[\mathbf{q}(t)]+[\mathbf{K}]\left[\left[\mathbf{T}^{\star}\right]\left[\mathbf{A}^{\star}\right][\mathbf{q}(t)]+\left[\mathbf{T}^{\star}\right]\left[\mathbf{c}^{\star}(t)\right]-[\mathbf{q}(t)]\right]
$$


The IIM and its dynamic extensions have been deployed in a number of applications, including inventory planning [Barker and Santos 2010a,b], workforce disruptions [Santos et al. 2009, Orsi and Santos 2010], electric power outages [Anderson et al. 2007, a and Barker 2012], and the 2011 Japanese earthquake and tsunami [MacKenzie et al. 2012b], among many others. Multiregional IIM models have been deployed for studying crude-oil loss impacts [Crowther and Haimes 2010] and multi-modal transport disruptions [MacKenzie et al. 2012a, Pant et al. 2011, 2012].

\subsection{Disruption Metrics}

As we are measuring the dynamic, multi-regional effects of transportation disruptions, such disruptions must be parameterized in the structure of Eq. (8). Since the transportation system facilitates the flow of commodities across regions, the inability of the waterway transportation mode to maintain functionality manifests itself as export and import losses for industries that make use of the waterway. We model export-import losses in terms of inoperability and demand perturbations along similar lines to previous work deploying the static MRIIM [Pant et al. 2011].

The economic input-output balance shown in Appendix Table A1 informs the process for translating export and import losses into the dynamic inoperability model. At time $t$, consider a commodity $i$ (from industry $i$ ) in region $r$ that is being exported out of $r$ along a waterway network. Exports signify end usage for the product that the industry makes, hence they belong to the final demand measure $c_{i}^{r}(t)$ for industry $i$ in region $r$. As such, any loss of export along the waterway network would contribute towards the demand perturbation $c_{i}^{\star r}(t)$. If $\Delta e_{i}^{r}(t)$ is the amount of export loss due to a transportation disruption, assuming as-planned industry output $x_{i}^{r}$ is constant for all $t$, then demand perturbation is calculated with Eq. (9).

$$
c_{i}^{\star r}(t)=\frac{\Delta e_{i}^{r}(t)}{x_{i}^{r}}
$$

While export contributions toward input-output metrics are straightforward to understand and quantify, import substitutions are more complicated. Typically in input-output tables [BEA 2011], imports are value-added contributions towards sector outputs. If $\Delta m_{i}^{r}(t)$ is the timedependent amount of commodity $i$ import loss into region $r$ due to a transportation disruption, then its contribution $\tilde{q}_{i}^{r}(t)$ toward industry $i$ inoperability is expressed in Eq. (10). This formulation is obtained by assuming the supply-side input-output inoperability balance within a region. Derived from the supply-side economic input-output balance shown Appendix Table A1, the supply side IIM balance is expressed as $q_{i}=\sum_{i=1}^{n} a_{i j}^{\star} q_{i}+w_{i}^{\star} \Rightarrow\left(1-\sum_{i=1}^{n} a_{i j}^{\star}\right) q_{i}=w_{i}^{\star}$, where $w_{i}^{\star}$ denotes the perturbations on the supply-side (imports and value-added). Hence for import disruptions $w_{i}^{\star}=\frac{\Delta m_{i}^{r}(t)}{x_{i}^{r}}$, which leads to Eq. (10).

$$
\tilde{q}_{i}^{r}(t)=\frac{1}{1-\sum_{j=1}^{n} a_{j i}^{\star r}}\left(\frac{\Delta m_{i}^{r}(t)}{x_{i}^{r}}\right)
$$


Since the dynamic MRIIM also provides sector inoperability $q_{i}^{r}(t)$ from previous time periods, we need to compare inoperabilities from Eqs. (8) and (10), where the maximum of the two values provides actual sector inoperability at the time period $t$. This suggests that inoperability in industry $i$ can only be as large as (i) the physical inoperability experienced in $i$ itself, or (ii) the inoperability caused by the interdependent nature of disruptions in other industries [Barker and Santos 2010a]. Hence the final inoperability is obtained from the Eq. (11) formulation, borrowing notation from MacKenzie et al. [2012].

$$
\hat{q}_{i}^{r}(t)=\max \left\{\tilde{q}_{i}^{r}(t), q_{i}^{r}(t)\right\}
$$

While there are several kinds of disruptions, any of which can be incorporated into transportation flow analyses, we are primarily interested in modeling impacts due to export-import losses, thus quantifying lost multi-regional, multi-regional commerce due to disruptions in infrastructure.

\subsection{Recovery Planning}

The dynamic multi-regional, multi-industry model in Eq. (8) allows for the estimation of individual, as well as interdependent, sector resilience with $\mathbf{q}(0)$ measuring the extent of initial impact and $[\mathbf{K}]$ providing a measure of the speed of recovery. Estimating the elements of [K] allows us to control recovery trajectory towards stable and acceptable inoperabilities for all sectors. For enhanced post-disaster recovery, economic sectors would prefer to maintain resources and make investments. Such planning behaviors are reflected in the values of the diagonal elements of [K]. Lian and Haimes [2006] suggest a means for estimating the elements of [K] as a function of (i) initial inoperability, (ii) an acceptable inoperability level signifying recovery, (iii) the time to attain the acceptable inoperability, and (iv) the diagonal elements of $\left[\mathbf{A}^{\star}\right]$, or the sector dependence on itself. We use a similar approach to parameterize $[\mathbf{K}]$, also incorporating sector adaptability to disruption preparation based on its own capacity.

If an industry $i$ in region $r$ has a resilience value of $k_{i i}^{r}=1$, then its inoperability in the next time period does not depend directly on its previous inoperability value (i.e., supply is not directly disrupted). This means that the sector is resilient to direct disruptive economic effects through risk management investments (e.g., inventory), and demand losses drive inoperabilities. Since finite inventory is available, it will be possible to maintain $k_{i i}^{r}=1$ only up to a certain level of inoperability. The sector resilience coefficient is quantified in Eq. (12) and thus explained. If industry $i$ in region $r$ can substitute for inoperability up to a threshold level $g_{i}^{r}$, then $k_{i i}^{r}=1$ until the time its inoperability lies below the threshold. This can be thought of as the industry's inherent resilience [Rose 2004]. If at time $T_{e}$, industry inoperability crosses the threshold, then the industry makes an investment in resilience, which takes it exponentially from a higher inoperability level $q_{i}^{r}\left(T_{e}\right)$ to a lower acceptable inoperability of $q_{i}^{r}\left(T_{e}+T_{f}\right)$ in a time span of $T_{f}$. The exponential function in Eq. (12) represents adaptive resilience [Rose 2004] investment by the industry. 


$$
k_{i i}^{r}=\left\{\begin{array}{cl}
1 & \forall t \text { until } 0 \leq q_{i}^{r}(t) \leq g_{i}^{r} \\
\frac{1}{T_{f}\left(1-a_{i i}^{\star r}\right)} \ln \left(\frac{q_{i}^{r}\left(T_{e}\right)}{q_{i}^{r}\left(T_{e}+T_{f}\right)}\right) & \forall t \geq T_{e} \text { if } g_{i}^{r} \leq q_{i}^{r}\left(T_{e}\right) \leq 1
\end{array}\right.
$$

Generally, large infrastructure systems are spread across wide geographic areas and have substantial inherent resilience capabilities, allowing them to substitute for disruptive losses. As such, the threshold values for industries would represent substantial damages to the infrastructures from extreme disruptive events.

\section{NeTWORK MOdel OF PORT AND WATERWAY EXPORT AND IMPORT LOSSES}

Some elements of Eq. (8) are parameterized with publicly available datasets, including [ $\left.\mathbf{A}^{\star}\right]$ [BEA 2011] and [ $\left.\mathbf{T}^{\star}\right]$ [BTS 2011]. The remaining parameters require disruption-specific parameters, the estimation of which is discussed in this section.

We propose network representations to model commodity flows through the waterway. Like any transportation system, a waterway network can be modeled as a graph consisting of nodes and edges. Nodes represent port facilities along the waterway system, while edges represent the portions of the navigable sections of the waterways. Figure 1 illustrates the inland waterway network constructed in this study. Each commodity being transported along this network is tracked by its unique description (commodity ID or name), position (spatial/temporal) and quantity. Further, the node (port) operations are modeled as queueing systems that represent dock operations for handling commodity arrivals and departures. In essence the network models represents the commodity supply chain from a port of entry to a port of exit. In the subsequent subsections we explain the node (port) and edge (waterway) flows through the network.

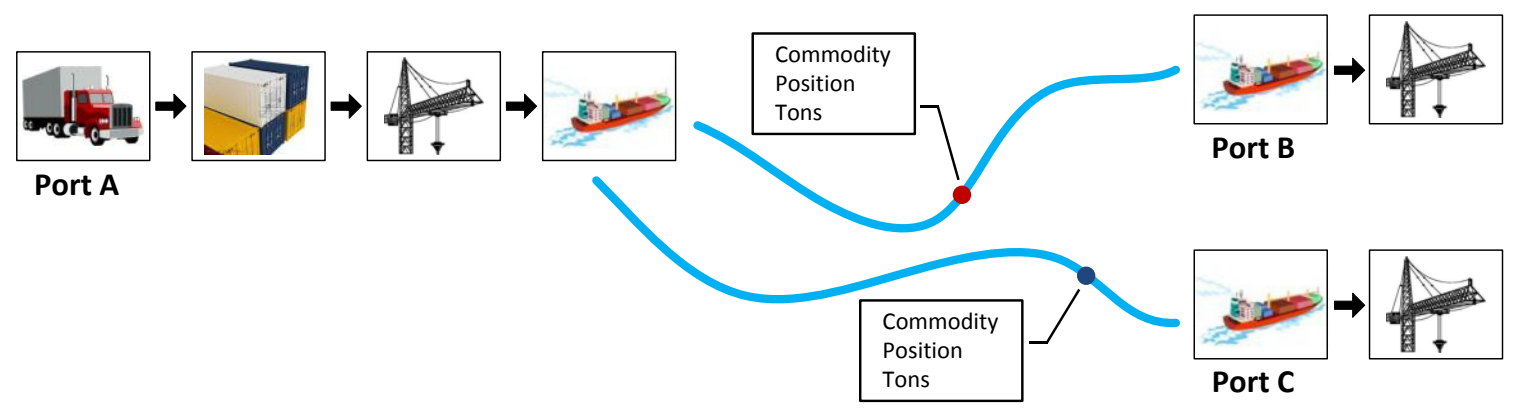

Figure 1. General representation of the inland waterway transportation network.

Once we have a network model for as-planned commodity flows, disruptive scenarios can be introduced by controlling/stopping flows along different network components over time for different locations.

\subsection{Node (Port) Operations}

Several modeling approaches have been applied in transportation studies for different types of transfer facilities [Simao and Powell 1992, Lee et al. 2003, Sacone and Siri 2009, Lee and Kim 
2010]. We use a simple discrete-event simulation model for commodity arrivals and departures at different docks of an inland port facility described by Pant et al. [2011].

Port operations are divided into four components, as illustrated in Figure 2: (i) delivery/receipt, including the truck/train arrival of export commodities and departure of imported commodities, (ii) yard operations, defined as the temporary storage of commodities at the port, (iii) crane operations, used to load and unload to and from port docks, and (iv) shipment, or the departure of commodities for export and the arrival of commodities for import. Similarly, import operations are divided into operations at different components of the port. A brief summary of the discreteevent model is provided in this section, though readers are directed to a more extensive discussion in Pant et al. [2011].

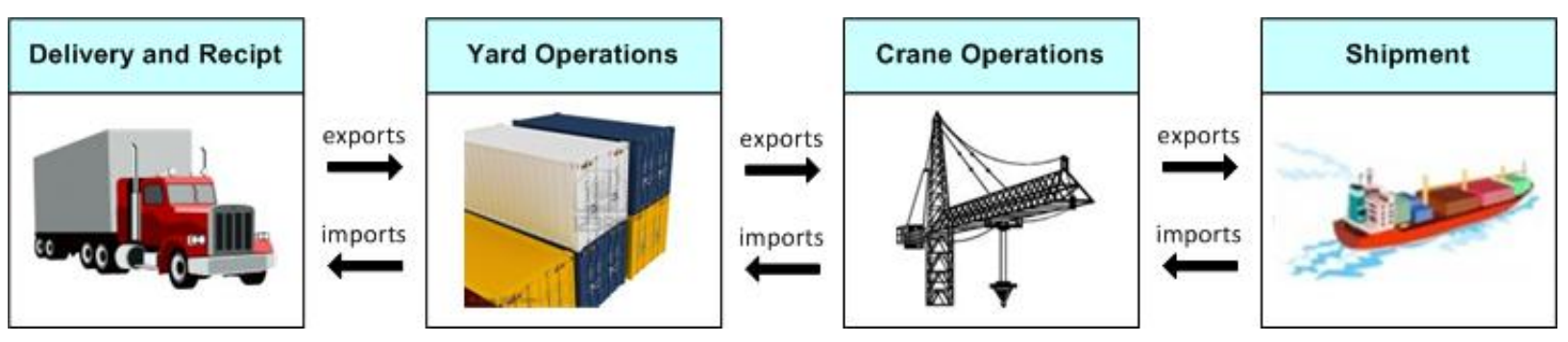

Figure 2. General representation of main inland port operations.

It is assumed that each commodity arriving at the port can be represented by its unique queuing process, which is independent of other commodities. For a time increment of $\Delta t$, the discrete time model captures the evolution of a commodity queueing model at all times $t(=0, \Delta t, 2 \Delta t, \ldots)$. Further, for purposes of tracking the commoidity through the network we also assign its port to origin and the port of destination.

\subsubsection{Export Operations}

The following discrete-time random variables are defined to represent exports from port $A$ towards port $B$ : (i) $Y_{i}^{A B}(t)$ is the number of units of commodity $i$ arriving at a terminal of port $A$ headed towards port B in the time interval $(t-\Delta t, t]$; (ii) $N_{i}^{A B}(t)$ is the number of units of commodity $i$ in yard storage at time $t$ after commodities have arrived in the interval $(t-\Delta t, t]$; (iii) $V_{i}^{A B}(t)$ is the maximum units of commodity $i$ that can be transferred by the cranes to the docks in the time interval $(t, t+\Delta t]$; (iv) $D_{i}^{A B}(t)\left(=E_{i}^{A B}(t)\right.$ for exports) is the number of units of commodity $i$ that are transferred to the dock for shipment from the port A to port B in the time interval $(t, t+\Delta t]$.

Based on the above definitions, the number of units of commodity $i$ stocked in the yard at time $t$ $+\Delta t$ is shown in Eq. (13) as the sum of the units remaining at the yard at the end of the previous time period and the units that arrive during the current time interval. From Eq. (14), the number of units of commodity $i$ transferred by cranes is the smaller of the number of units at the yard and crane capacity, and under normal port operations this represents the units of commodity exported.

$$
N_{i}^{A B}(t+\Delta t)=\max \left[0, N_{i}^{A B}(t)-V_{i}^{A B}(t)\right]+Y_{i}^{A B}(t+\Delta t)
$$




$$
E_{i}^{A B}(t)=D_{i}^{A B}(t)=\min \left[N_{i}^{A B}(t), V_{i}^{A B}(t)\right]
$$

\subsubsection{Import Operations}

Similar to the quantification of export operations, the following discrete-time random variables are defined for the import operations at port $A$ from port $B$ : (i) $Y_{i}^{B A}(t)$ is the number of units of commodity $i$ arriving at a terminal of port $A$ from port B in the time interval $(t-\Delta t, t]$; (ii) $N_{i}^{B A}(t)$ is the number of units of commodity $i$ in yard storage at time $t$ after import commodities have arrived in the interval $(t-\Delta t, t]$; (iii) $W_{i}^{B A}(t)$ is the maximum units of import commodity $i$ that can be loaded from the yard to trucks or trains in the time interval $(t, t+\Delta t]$; (iv) $D_{i}^{B A}(t)$ $\left(=I_{i}^{B A}(t)\right.$ for imports) is the number of units of commodity $i$ that depart from the port A for further road or rail transport in the time interval $(t, t+\Delta t]$.

Imported commodities arrive at the docks and are transferred from the cranes to the yards. Eq. (15) describes the number of units of commodity $i$ transferred by the cranes, calculating the number of units of commodity $i$ at the yard as the sum of the units remaining and the units transferred. Under normal port operations, the number of units of commodity $i$ departing the port are equal to the units transferred by the crane, as shown in Eq. (16).

$$
\begin{gathered}
N_{i}^{B A}(t+\Delta t)=\max \left[0, N_{i}^{B A}(t)-W_{i}^{B A}(t)\right]+Y_{i}^{B A}(t+\Delta t) \\
I_{i}^{B A}(t)=D_{i}^{B A}(t)=\min \left[N_{i}^{B A}(t), W_{i}^{B A}(t)\right]
\end{gathered}
$$

In the models above, the arrival of commodities, the service capacities of cranes, and the import loading process, would likely be known from port data sources. As such, the remaining random variables are calculated differently depending on the nature of the arriving and departing commodity (export or import). Within the queuing models, the arrivals of commodities are modeled as independent non-stationary Poisson processes $\left(\lambda_{i}(t)\right.$ for commodity $\left.i\right)$. The rate of service for the crane operations at the terminal is modeled as a Poisson process with timedependent rates $\left(\mu_{i}(t)\right.$ for commodity $\left.i\right)$.

\subsection{Edge (Waterway) Operations}

In the inland waterway network, the waterway under consideration is treated as a port-to-port connector. Unlike highway networks, where several alternate paths exist between sources and destinations, inland waterway networks have fixed navigable routes because there is one section, or perhaps a few sections, of the river that allows for transport. As such, the edge between two ports is considered unique. For tracking transportation along the river, we divide the river into sections based on estimates of distance covered by barges at a given time. The units commodity $i$ entering the edge connecting port $A$ and port $B$ are now represented by their time $t$ and position

( $l$, latitude-longitude) $D_{i}^{A B}(t, l)$ on the edges. If the velocity of barge transport $(v)$ is known, then the units of commodity $i$ on the network in the next time and distance increments are given by Eq.(17). 


$$
D_{i}^{A B}(t+\Delta t, l+\Delta l)=D_{i}^{A B}(t, l+v \Delta t)
$$

\subsection{Network Disruptions}

Commodity flows can be disrupted in two ways along the waterways: (i) if a port facility is fully or partially out of service due to the suspension of dock operations, or (ii) if a river channel is not navigable due to flooding, freight accidents, or delays. The network model developed above is capable of modeling flows at the port level and also along the waterway during both normal and disruptive flow conditions.

\section{Network damage state at time $t$}

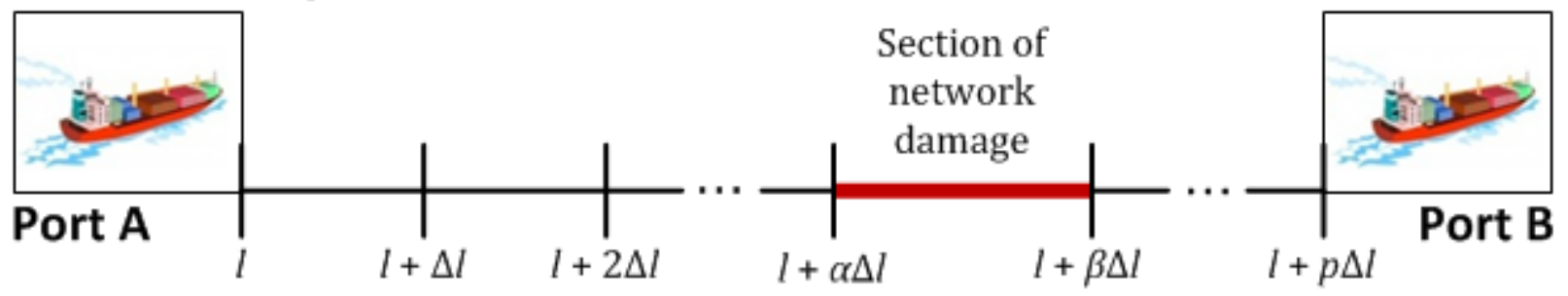

Figure 3. Representation of a generalized network flow disruption on an inland waterway network.

The outcome of a shock event at time $t$ is represented with the disruption of flows it causes over a particular section of the network. As shown in Figure 3, the generalized representation of the disruption of the commodity flows between Ports $A$ and $B$ at time $t$ is given in terms of the extent of the network section from $l+\alpha \Delta l$ to $l+\beta \Delta l$ (with Port A as reference position $l$ ) where the disruption occurs. Assuming the rest of the waterway section is functional, the loss of commodity $i$ between ports $A$ to $B$ is the $\sum_{k=\alpha}^{\beta} D_{i}^{A B}(t, l+k \Delta l)$, which represents the exports headed from $A$ to $B$. Similarly, the loss of commodity $i$ between ports $B$ to $A$ is the $\sum_{k=\beta}^{\alpha} D_{i}^{B A}(t, l+k \Delta l)$, which represents the imports headed from $B$ to $A$. Assuming all the classes of cargo lost are measured in monetary units, the network damages can be translated to export-import values that provide inputs to the Eq. (8) model. In particular, the commodity-wise regional export loss value $\left(\Delta e_{i}^{r}(t)\right)$ from Eq. (14) is related to the network losses by the Eq. (18) formulation. Here the export losses are summed over all the ports $A$ in region $r$ for which flows are disrupted taking into account at the port $B$ to where commodity $i$ is being transported.

$$
\Delta e_{i}^{r}(t)=\sum_{\forall A \in r} \sum_{\forall B} \sum_{k=\alpha}^{\beta} D_{i}^{A B}(t, l+k \Delta l)
$$

Likewise, regional import loss of commodity $i\left(\Delta m_{i}^{r}(t)\right)$ in Eq. (10) is estimated from Eq. (19). Again import losses are summed over all the ports $A$ in region $r$ for which flows are disrupted taking into account at the ports $B$ from where commodity $i$ is being imported.

$$
\Delta m_{i}^{r}(t)=\sum_{\forall A \in r} \sum_{\forall B} \sum_{k=\beta}^{\alpha} D_{i}^{B A}(t, l+k \Delta l)
$$


We note here that commodity losses have an impact on the economies of multiple regions because the exports for one region are the imports for another, which implies for same flow disruption needs to be translated to export losses $\left\{\Delta e_{i}^{r}(t), \Delta e_{i}^{S}(t), \ldots\right\}$ and import losses for all $\left\{\Delta m_{i}^{r}(t), \Delta m_{i}^{s}(t), \ldots\right\}$ for all regional ports affected by the disruption.

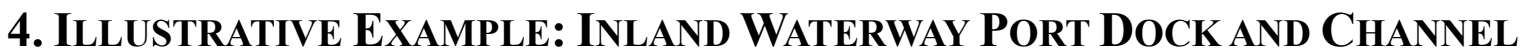 DISRUPTIONS}

To demonstrate the methodology outlined in the previous sections, a case-study analysis is done for the inland waterway network shown in Figure 4. The network shows a section of the Mississippi River Navigation System, considered the most important commercial navigation corridor in the US. A section of this network is the McClellan-Kerr Arkansas River Navigation System (MKARNS), including the Port of Catoosa located near Tulsa, Oklahoma. This study for the Port of Catoosa illustrates the dock-specific discrete-event queueing models for disrupted commodity flows and dynamic multi-regional, multi-industry model.

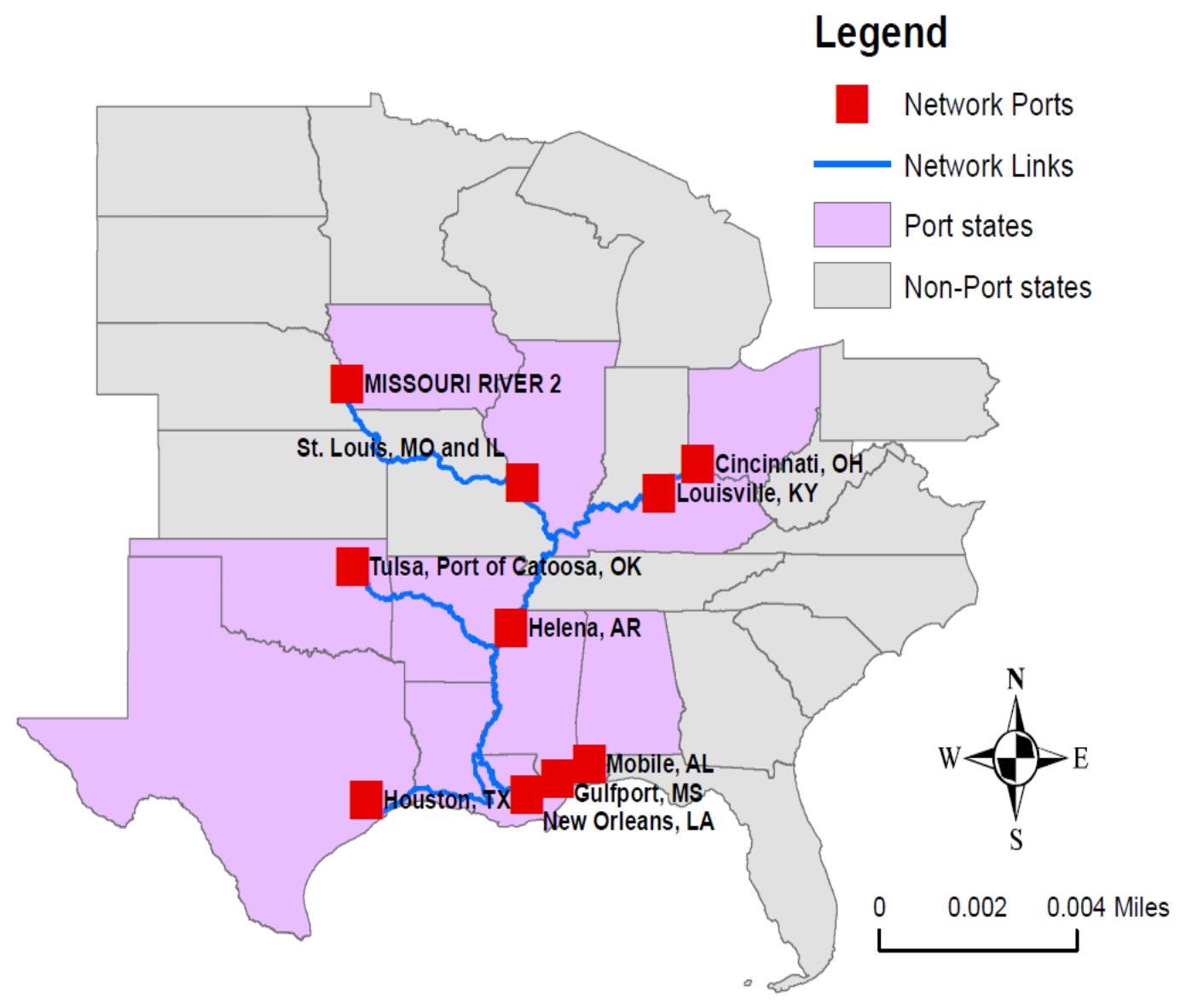

Figure 4. Inland waterway network chosen for the case study.

The port is an important transportation hub for the Midwest, as it is the northernmost inland port that remains unfrozen all year long. Commodities of many types, including grains, fertilizers, 
metal products, and chemicals, are shipped both in and out of the port. The port provides services for many states, including Alabama, Arkansas, Illinois, Iowa, Kentucky, Louisiana, Mississippi, Ohio, Oklahoma, and Texas. The primary industries (using the North American Industry Classification System (NAICS) [OMB 2007] sector titles, the official infrastructure and industry sectors for which BEA data are collected) shipping through the Port of Catoosa are found in Table 1. The annual exports and imports through the Port of Catoosa for these states in tons provided in Table A3 of the Appendix are converted to US\$ million and shown Figure 5. The network Figure 4 shows the ports where commodities are assumed to be transported for the network model connecting the trading states. Here we have assumed that there is one main port for each state that trades export/imports with Catoosa. All data and mode assumptions are obtained from the integration of Bureau of Transportation Statistics [2013], US Army Corps of Engineers [2013], and Port of Catoosa [2013] databases.

Table 1. Names of the main industries using the Port of Catoosa.

\begin{tabular}{l}
\hline Industry name \\
\hline Food and beverage and tobacco products \\
Petroleum and coal products \\
Chemical products \\
Nonmetallic mineral products \\
Primary metals \\
Fabricated metal products \\
Machinery \\
Miscellaneous manufacturing
\end{tabular}

The Port of Catoosa has four main docks, each of which deals with a specific commodity type [Pant et al. 2012]. The Dry Cargo dock handles large items, primarily steel, iron, and machinery. The specific sectors that are primarily affected by the Dry Cargo dock are Primary Metals, Machinery, Fabricated Metals, and Miscellaneous Manufacturing. The Dry Bulk dock handles a variety of loose commodities that are moved by conveyer, such as sand, gravel, and fertilizer, the primary NAICS sector for which is Minerals. The Grains dock moves agricultural products such as corn, wheat, and soybeans, with Food and Beverage Products being the primary NAICS sector. Finally, the Liquid Bulk dock moves liquid products including chemicals, liquid fertilizers, and even molasses. The two primary NAICS sectors whose commodities flow through the Liquid Bulk dock are Chemicals and Petroleum Products. The commodity flows for these eight NAICS sectors through the Port of Catoosa are also provided in Figure 5. If any of the four docks becomes inoperable, it would stop the flow of the specific type of commodity handled by that dock. The flows disruptions to these industries/commodities in Figure 5 are the inputs for the port and network simulation model, and further to the multi-regional multi-industry inoperability model. 

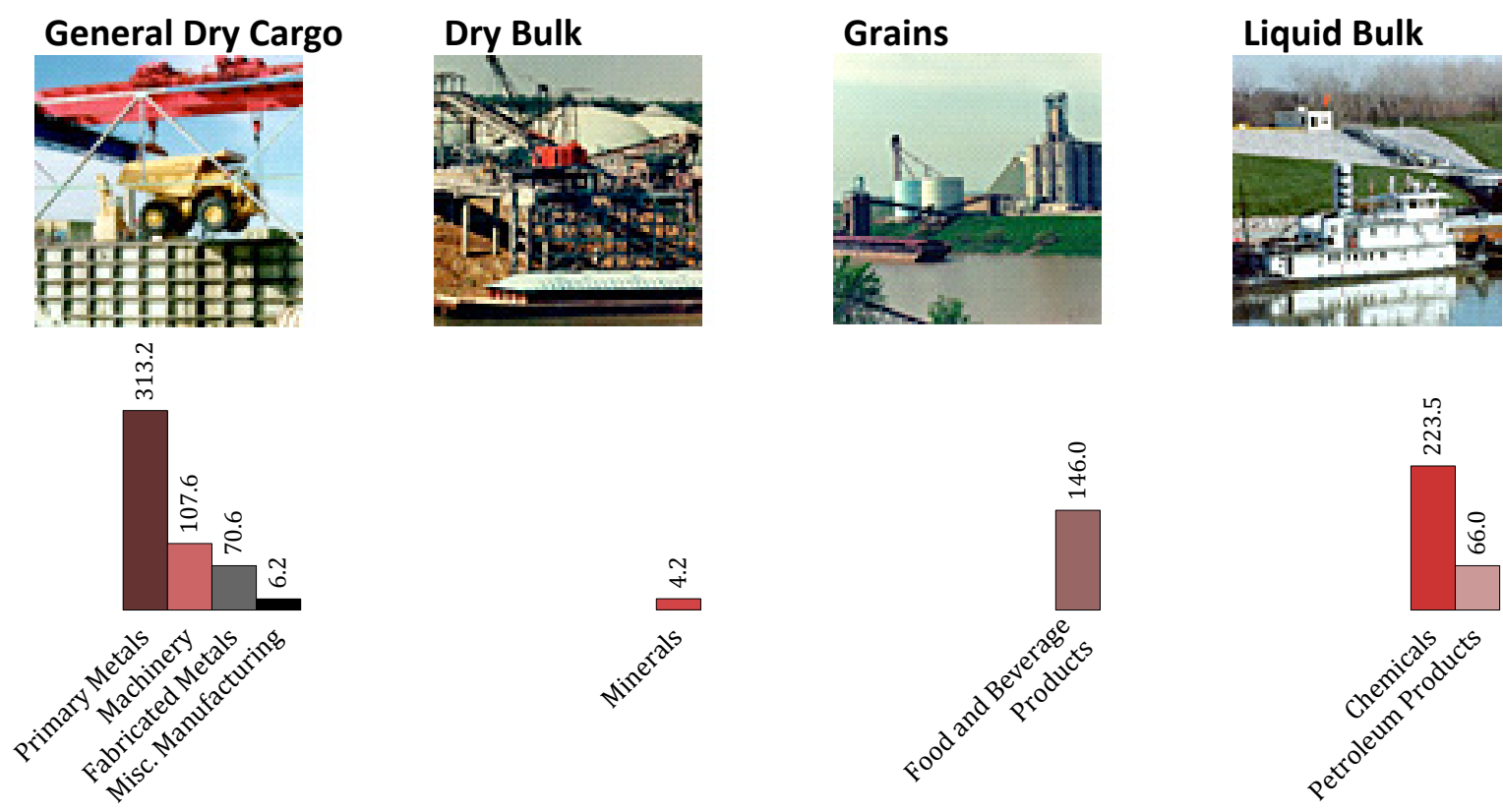

(a)

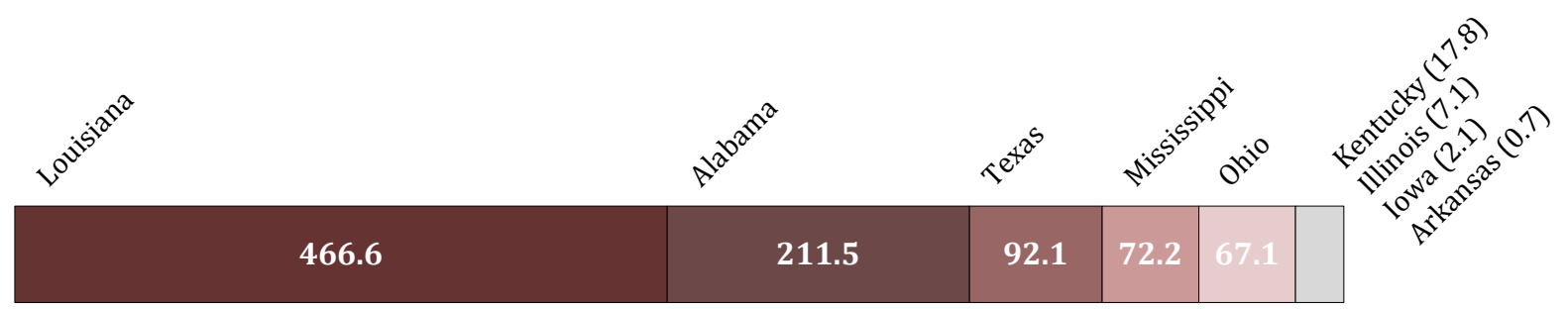

(b)

Figure 5. Estimates for the 2007 annual export-import commerce through the Port of Catoosa for (a) specific docks located at the Port and (ii) main trading states benefiting from the Port, in US \$ million.

\subsection{Port Disruption}

There are a number of natural and man-made events that could cause disruptions in the movement of commodities through the Port of Catoosa. For example, in May of 2002, an Interstate 40 bridge spanning the Arkansas River collapsed when a barge struck a pylon, shutting down barge traffic for over two weeks [USDOT 2008]. Flooding events of the waterway greatly reduce the number of barges that could be moved through [Koetse and Rietveld 2009]. A fire at a fertilizer company in early 2009 led to chemical run-off into the port, which required clean up before it spread [Harper 2009]. Events such as the bridge collapse and flooding affect the entire port's capacity to move product, whereas a fire and the subsequent cleanup affect one or more docks.

The annual port commerce statistics from Table A3 are converted to daily commodity flows. The port is in operations for five days a week for 50 weeks of the year. Also flows vary seasonally, a factor that is taken into consideration when calculating the daily flows [Pant et al. 2011]. The final flow values are assumed to be the parameters $\left(\lambda_{i}(t)\right)$ to simulate non-stationary Poisson 
arrivals at the ports. Converting to daily flows implies $\Delta t=1$, which is also the time step of the Eq. (8) model. The crane operating capacities for the docks, used in Eqs. (13)-(16), are [Tulsa Port of Catoosa 2013]: (i) 1600 tons/day for Dry Cargo, (ii) 400 tons/day for Dry Bulk, (iii) 2500 tons/day for Grains. For the Liquid Bulk dock capacities are not constrained because these commodities are transferred through high-pressure pipes. For other ports in the network the same capacity crane capacities are assumed. Once a barge leaves a port it travels on the waterway at an average speed of 100 miles per days [Tulsa Port of Catoosa 2013]. Hence, from the network route lengths, the times required for the exports/import to reach from other ports to the Port of Catoosa can be estimated. The daily commerce estimates suggest that exports and imports are not limited by crane operations. For example, Figure 6 shows the time-series over the year of exports and imports of Chemical Products arriving at the Liquid Bulk dock of Port for Catoosa, which reflects the seasonality of the flows.

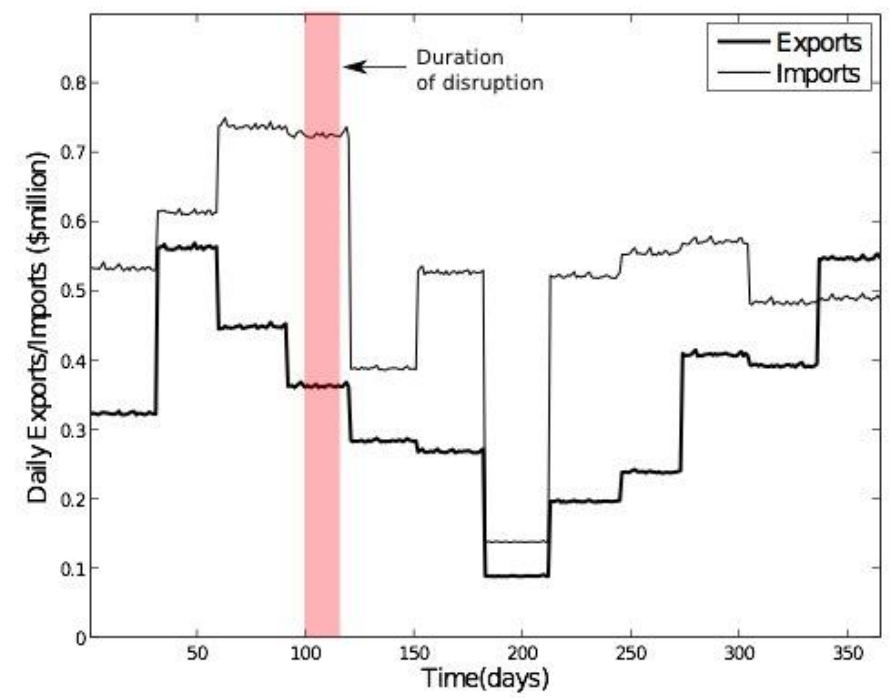

Figure 6. Time-series of daily exports and imports of Chemical products sectors arriving at the Port of Catoosa.

We consider a closure of the Port of Catoosa over a duration of two weeks and model the local and multi-regional effects of such a disruption. As shown in Figure 6, a day of the year $(t=100)$ when a disruptive event occurs is chosen, and overall port and local waterway commerce ceases for a two-week duration $(t=(100,113))$. In the port model, the disruptions manifest with the stopping of the arrival and departure queues in the Port of Catoosa supply chain, and commodities do not enter the flows. Table 2 shows the mean estimates for the direct daily supply inoperabilities, $\left(\tilde{q}_{i}^{r}(t)\right.$ from Eq. (10)) and demand perturbations $\left(c_{i}^{\star r}(t)\right.$, Eq. (9)) terms that are inputs into the multi-regional inoperability model Eq. (8). 
Table 2. The mean estimates over 2-week for direct supply inoperabilities $\left(\widetilde{q}_{i}^{r}(t)\right.$, Eq. (10)) $\left(\mathbf{x 1 0}^{-3}\right)$ and demand perturbations $\left(c_{i}^{\star r}(t)\right.$, Eq. (9)) $\left(\mathrm{x10}^{-3}\right)$ for export-imports disruptions. The superscripts indicate whether the number is a supply effect $\left(S, \widehat{q}_{i}^{r}(t)\right)$, demand effect $\left(D, c_{i}^{\star r}(t)\right)$ or both $(S+D)$.

\begin{tabular}{|c|c|c|c|c|c|c|c|c|}
\hline \multirow[t]{2}{*}{ State } & \multicolumn{8}{|c|}{ Industry } \\
\hline & $\begin{array}{c}\text { Food/ } \\
\text { Beverage }\end{array}$ & $\begin{array}{c}\text { Petro/ } \\
\text { coal }\end{array}$ & $\begin{array}{l}\text { Chem. } \\
\text { products }\end{array}$ & $\begin{array}{c}\text { Non- } \\
\text { metallic }\end{array}$ & $\begin{array}{c}\text { Primary } \\
\text { metals }\end{array}$ & Fab metal & Machinery & $\begin{array}{l}\text { Misc. } \\
\text { manfg. }\end{array}$ \\
\hline $\mathrm{AL}$ & $0.04^{\mathrm{S}}$ & & & & $0.53^{\mathrm{D}}$ & $0.23^{\mathrm{D}}$ & & \\
\hline $\mathrm{AR}$ & & & & $0.02^{\mathrm{D}}$ & & & & \\
\hline IL & $0.002^{\mathrm{D}}$ & & $0.03^{\mathrm{D}}$ & $0.003^{\mathrm{S}}$ & & & & \\
\hline IA & $0.006^{\mathrm{D}}$ & & & & & & & \\
\hline $\mathrm{KY}$ & & & $0.07^{\mathrm{S}}$ & & & & & \\
\hline LA & $0.58^{\mathrm{S}+\mathrm{D}}$ & $0.013^{\mathrm{S}+\mathrm{D}}$ & $0.18^{\mathrm{D}}$ & & $2.05^{\mathrm{D}}$ & $0.19^{\mathrm{D}}$ & $0.26^{\mathrm{S}}$ & \\
\hline MS & & & $0.66^{\mathrm{S}+\mathrm{D}}$ & & & & & \\
\hline $\mathrm{OH}$ & & & & & $0.078^{\mathrm{D}}$ & $0.017^{\mathrm{D}}$ & & \\
\hline $\mathrm{OK}$ & $0.83^{\mathrm{S}+\mathrm{D}}$ & $0.16^{\mathrm{S}+\mathrm{D}}$ & $5.44^{\mathrm{S}+\mathrm{D}}$ & $0.065^{\mathrm{S}+\mathrm{D}}$ & $6.71^{\mathrm{S}+\mathrm{D}}$ & $0.49^{\mathrm{S}+\mathrm{D}}$ & $0.48^{\mathrm{S}+\mathrm{D}}$ & $0.32^{\mathrm{S}+\mathrm{D}}$ \\
\hline $\mathrm{TX}$ & & $0.0021^{\mathrm{s}}$ & & & & & $0.063^{\mathrm{S}}$ & $0.041^{\mathrm{S}}$ \\
\hline
\end{tabular}

D - Demand loss driven effect.

$\mathrm{S}$ - Supply loss driven effect.

S + D - Both supply and demand effects.

Figure 7 shows the dock specific cumulative loss of export-imports from the onset of the disruption till the port reopens. The Dry Cargo and Liquid Bulk docks experience highest exportimport losses due to volume and value of commerce through these docks. Overall, more losses are incurred for imports than exports, with total losses amounting to an estimated $\$ 45.0$ million for such a disruptive event.

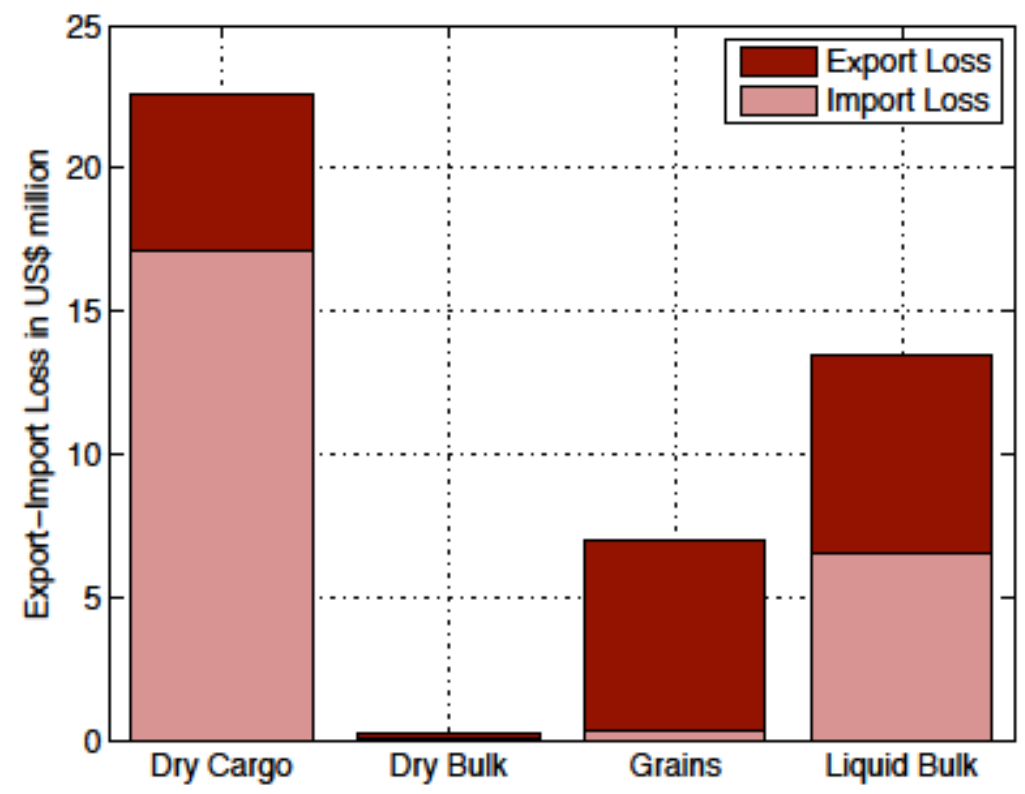

Figure 7. Dock-specific export-import losses due to a two-week port closure. 


\subsection{Multi-Regional, Multi-Industry Impacts}

While the primary industries using the Port of Catoosa are found in Table 1, the broader 63sector classification of commodities, which experience indirect losses due to the interdependent nature of industry interconnectedness, are provided in Table A2 in the appendix. Further, these broader industries are located regionally. The dynamic network model and the multi-regional inoperability model are informative about the temporal propagations of impacts over the region. For the network, the location of disruption corresponds to the Port of Catoosa coordinates. The cargo flow leaving a port is assumed to be disrupted at the time it reaches the Port of Catoosa, which is estimated from the length of the navigation route and travel speed of the cargo. For example, the network distance between ports in Catoosa and Houston is estimated as 720 miles, which means that the cargo leaving the Port of Houston eight days prior is disrupted when it reaches the Port of Catoosa. Export-import loss metrics are generated for the duration of disruption by estimating the amount of lost flow relative to a "no disruption" scenario as outlined in Eqs. (18) and (19). We also observe that the values of demand perturbations or supply inoperabilities due to such a localized disruption are small fractions compared to entire state economies, hence industry supplies are not impacted by such an event. This suggests that the diagonals of [K] equal 1 for the entire duration of the analysis. Figure 8 depicts the evolution of inoperabilites of the 63 industries in the Oklahoma and Louisiana economies between $t=90$ and $t=160$. The plots capture the onset of the flow losses until recoveries are complete across all sectors. As is expected, inoperability in Oklahoma industries is higher because the port disruption will impact the Oklahoma economy the most. The inoperability time-series in Figure 8 depicts an extended effect on Louisiana industries, which is the result of the export disruptions from Oklahoma and the time taken by the cargo to travel via the network. The estimated cargo travel-time between the Catoosa and New Orleans ports is 13 days, suggesting that the effects of any disruption of commodity exports at Oklahoma will be felt in the Louisiana economy after sseveral days. Such analysis highlights the importance of using the dynamic network and multiregional model for studying macroeconomic consequences. 

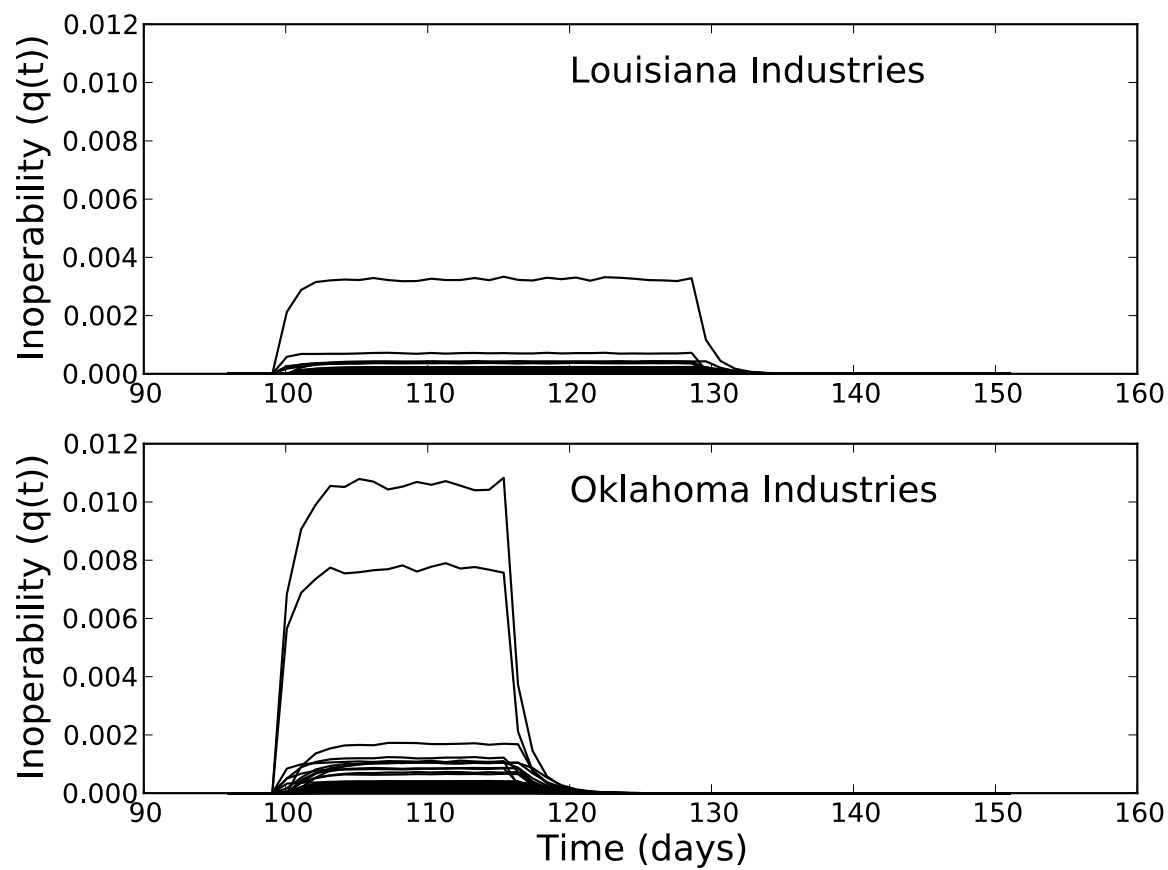

Figure 8. Dynamic inoperability evolution for industries in Louisiana and Oklahoma.

Out of many possible scenarios, presented here are the effects on Oklahoma industries due to a port closure. Figure 9 ranks the top 10 industries by the total amount of losses as a result of a closure of the entire port, noting that the ranking contains four industries that do not directly export or import through the port. Figure 10 shows such ranking due to closure of only the Dry Cargo dock, and similarly Figure 11 through Figure 13 show sector impacts due to the Dry Bulk, Grains and Liquid Bulk docks respectively. These results highlight the nature of the interdependent propagation of the impacts, which are important to understand for sector recoveries. 


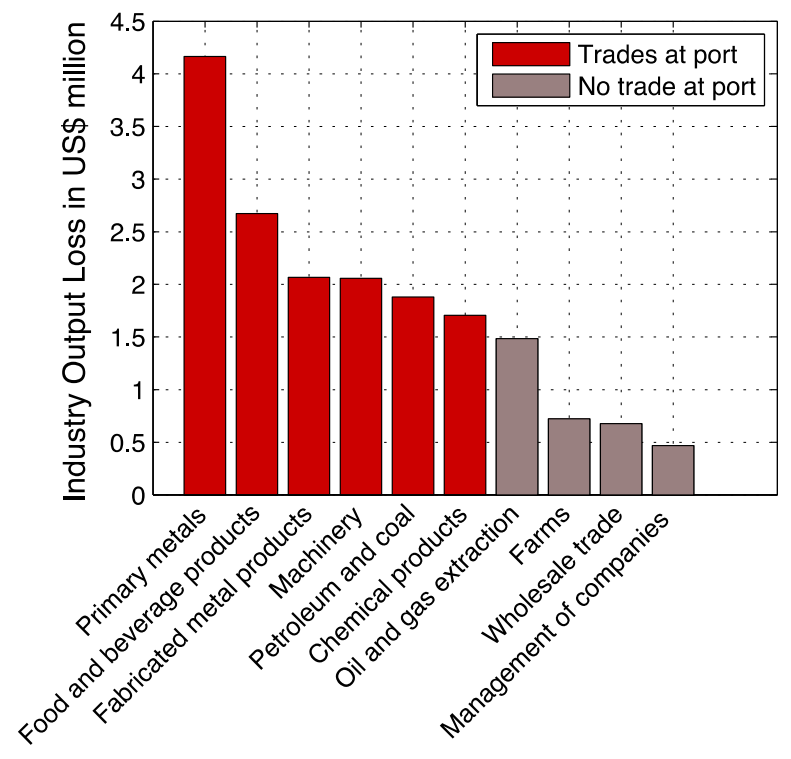

Figure 9. Output losses for Oklahoma industries due to total port shutdown.

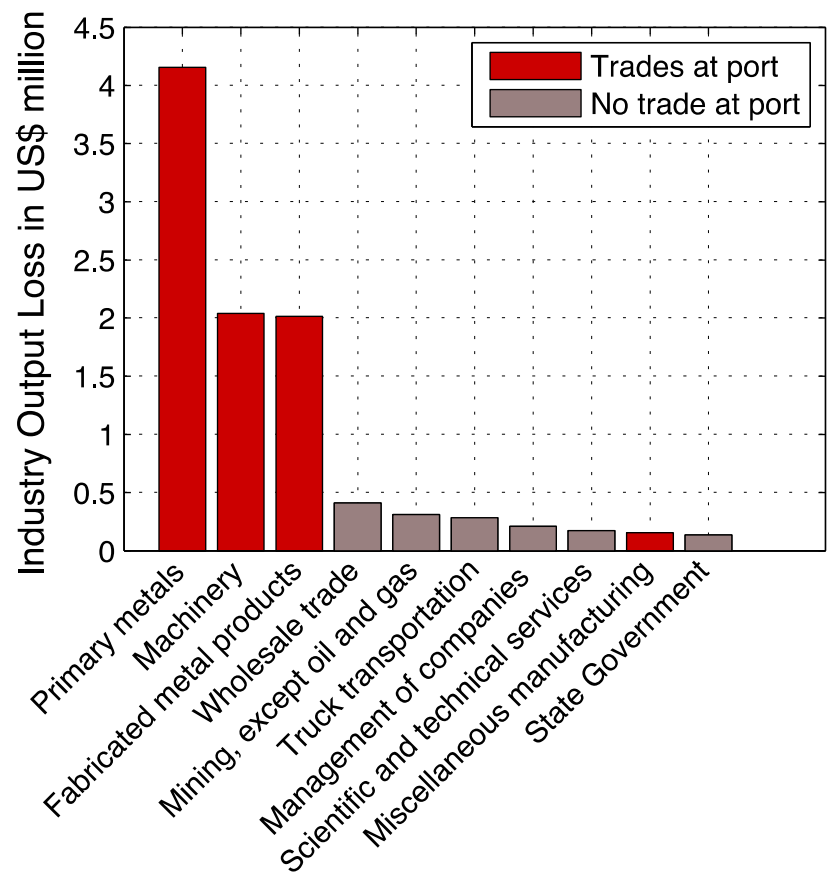

Figure 10. Output losses for Oklahoma industries due to Dry cargo dock shutdown. 


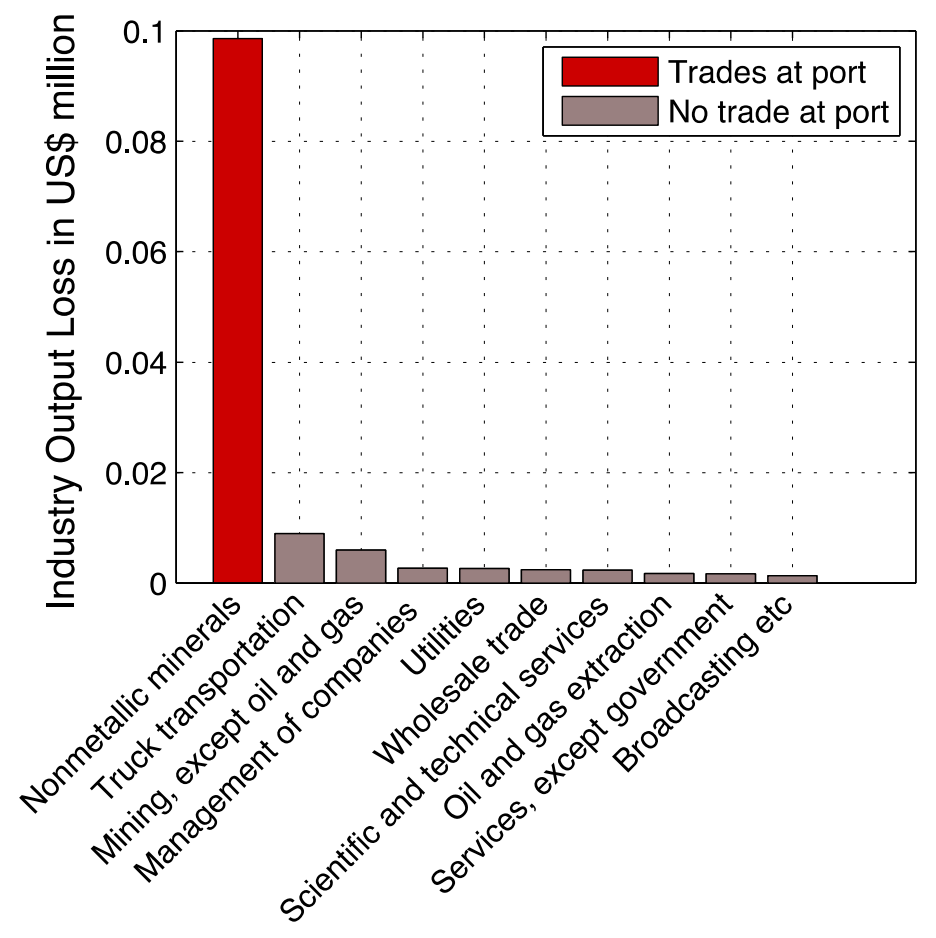

Figure 11. Output losses for Oklahoma industries due to Dry Bulk dock shutdown.

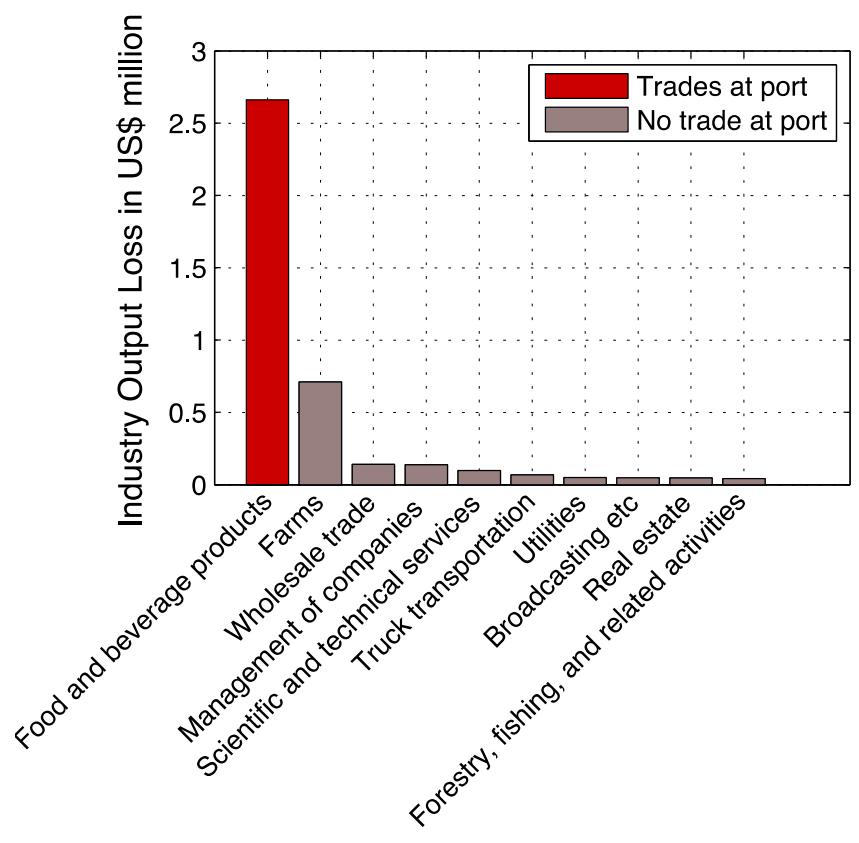

Figure 12. Output losses for Oklahoma industries due to Grains dock shutdown. 


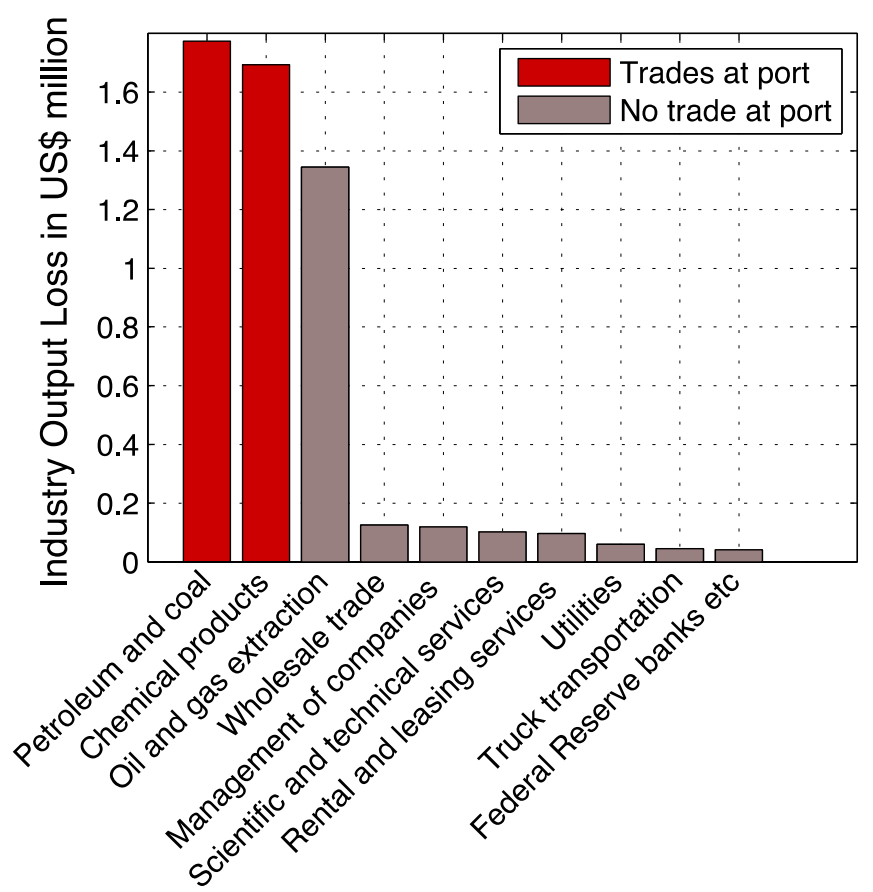

Figure 13. Output losses for Oklahoma industries due to Liquid Bulk dock shutdown.

Another aspect of port disruptions worth highlighting is the economic impact it has across multiregional economies. Figure 14 depicts the direct, indirect, and total losses for regional economics of the 10 states using the Port for commerce. In input-output modeling terms, direct losses come from the demand driven disruptions and are calculated as the sum of the $\left[\mathbf{T}^{\star}\right]\left[\mathbf{c}^{\star}(t)\right]$ vector in the Eq. (8). These contribute towards backward linkage effects [Miller and Blair 2009] of disruption propagation that result in indirect losses. Figure 14 suggests that total multi-regional direct losses across all 10 states are $\$ 111.8$ million resulting from a two-week port closure, accompanied by total indirect losses of $\$ 72.9$ million across all states. Such an analysis would suggest that multiple geographical areas have a stake in the resilience of transportation infrastructure to localized disruptions. 


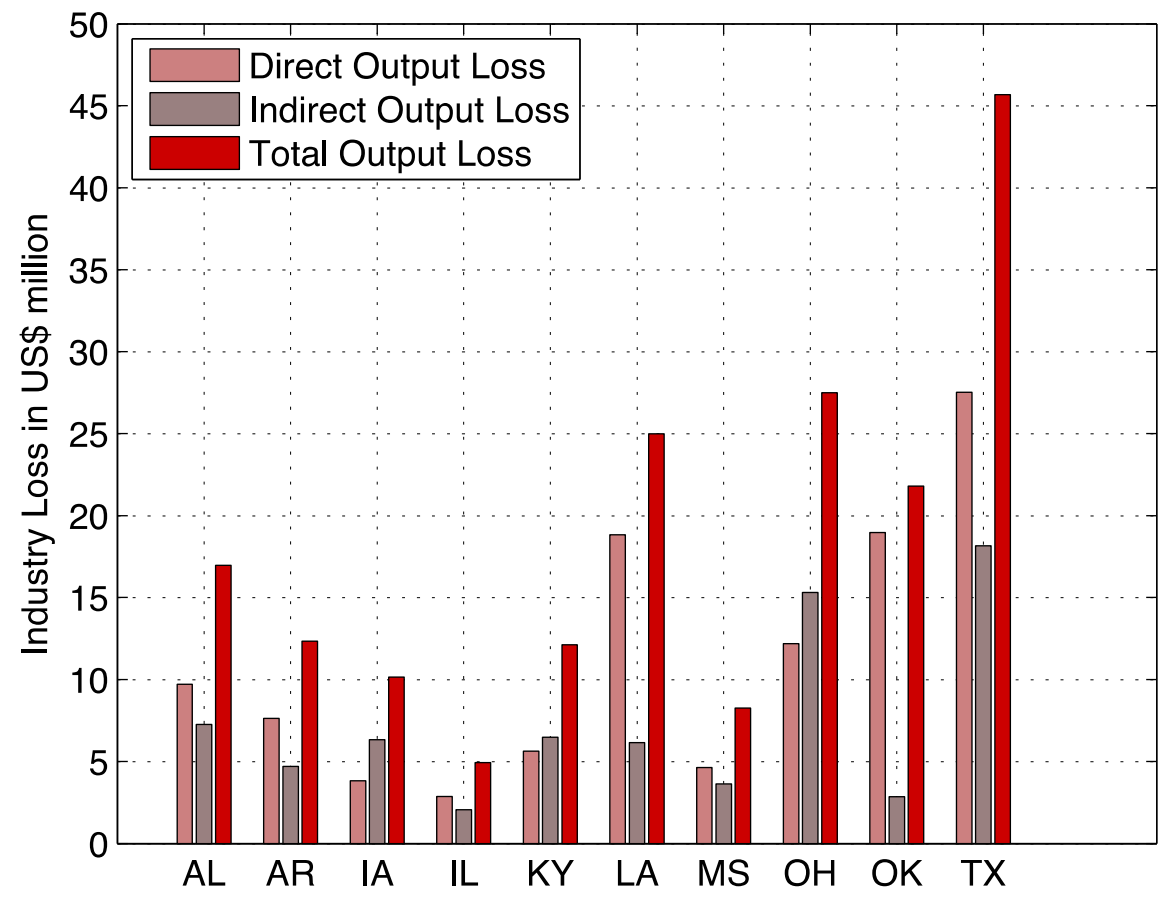

Figure 14. Estimates for industry direct and indirect losses from a two-week port closure across 10 states using the Port of Catoosa for commerce.

\section{CONCLUding REMARKS}

This study extends our previous work on multi-industry, multi-regional economic impact analysis of inland waterway port disruptions [Pant et al. 2011], and we make several contributions to the literature in multi-regional damage assessment for these little-explored, though vital, components of multi-modal commodity flows.

First, we provide a dynamic multi-regional interdependency model that captures the temporal and geospatial propagation of disruptions and subsequent recovery. Little work has explored dynamic multi-regional interdependency models, particularly applied to inland waterway disruptions. We have integrated these two research domains to produce a framework that provides suitable metrics for damage assessment. In developing the model, we have suggested a new scheme for estimating sector resilience that is adaptive to the level of disruptions and capacity of the sector. Second, the dynamic MRIIM deployed here is supported by detailed publicly available data, making such analyses practical. Third, a port commodity flow model is integrated here with a waterway network model for a more comprehensive analysis of disruption propagation. The case study calculations for a two-week port disruption show higher losses than previously discussed due to such improvements in the inoperability and network models.

The two-week disruption scenario for the inland Port of Catoosa in Oklahoma that we explore in this study shows that $\$ 45$ million export-import losses in port industries result in $\$ 111.8$ direct 
and \$72.9 indirect losses for industry sector across 10 states. The ranking of sectors with most losses further highlights the fact that interdependence results in substantial losses of sectors that do not directly operate at the port. The dock specific losses we present here give an indication of the impacts on the port and industries if disruptions were more localized.

The practicality of the results comes from the data used, which is provided by national accounts and port commerce statistics. Some studies on possible port closure scenarios based on simulations were done for the ports of Los Angeles and Long Beach. A one-week shutdown at the ports resulted in the ranges of daily losses from $\$ 65$ million to $\$ 150$ million [Arnold et al. 2006], when different shipping alternatives were incorporated into the models. A 2001 impact assessment study, which consider similar worst-case analysis as the study presented here, for the same West Coast ports forecast that a 10-day port closure would result in losses of $\$ 1.9$ billion per day [Martin Associates 2001]. The scale of such a coastal ports relative to the Port of Catoosa (roughly 100 times the value of commerce) suggests that results of this study appear reasonable.

These analyses can be used by decision makers in a numbers of ways. A dock-specific analysis may pinpoint port authority preparedness dollars in protecting and hardening dock infrastructure against disruptions. Identifying key industries allows downstream factories and other users of input commodities to potentially make preparedness decisions regarding inventory or substitution practices. Finally, understanding the multi-regional impact of shared infrastructure highlights the importance of interstate commerce and the wide-reaching impact of preparedness.

This work can be further extended to include other network- and dock-specific details into the model. Overall, this work serves as an initial blueprint for further complex multi-regional interdependent risk analysis along inland waterways. 


\section{REFERENCES}

American Society of Civil Engineers. 2013. Report Card for America's Infrastructure 2013.

Arnold, B., C. Cammarata, D. Farmer, K. Kowalewski, F.Lapido, M. Lasky, D. Moore. 2006.

The economic costs of disruption in container shipments, Congressional Budget Office, March 26, 2006.

Association of American Railroads. 2007. National Rail Infrastructure Capacity and Investment Study, prepared by Cambridge Systematics, Inc., Washington, DC.

Barker, K. and J.R. Santos. 2010a. Measuring the Efficacy of Inventory with a Dynamic InputOutput Model. International Journal of Production Economics, 126(1): 130-143.

Barker, K. and J.R. Santos. 2010b. A Risk-based Approach for Identifying Key Economic and Infrastructure Sectors. Risk Analysis, 30(6): 962-974.

Bureau of Economic Analysis. 2011. Interactive Access to Input-output Accounts Data. $<$ http://www.bea.gov>.

Bureau of Transportation Statistics. 2011. 2007 Commodity Flow Survey Overview and Methodology. <http://www.bts.gov/publications/commodity_flow_survey/index.html/>.

Chang, S.E. 2000. Disasters and transport systems: loss, recovery and competition at the Port of Kobe after the 1995 earthquake. Journal of Transport Geography, 8(1): 53-65.

Crowther, K.G. and Y.Y. Haimes. 2010. Development and Deployment of the Multiregional Inoperability Input-output Model for Strategic Preparedness. Systems Engineering, 13(1): 28-46.

Dang, Q.-V., W.-Y. Yun, and H. Kopfer. 2012. Positioning Empty Containers under Dependent Demand Process. Computers and Industrial Engineering, 62(3): 708-715.

Department of Homeland Security. 2009. National Infrastructure Protection Plan: Partnering to Enhance Protection and Resiliency. Technical report, Department of Homeland Security.

Francesco, M.D., M. Lai, and P. Zuddas. 2013. Maritime Repositioning of Empty Containers under Uncertain Port Disruptions. Computers and Industrial Engineering, 64(3): 827-837.

Gordon, P., J.E. Moore, H.W. Richardson, M. Shinozuka, A. Donghwan, and S. Cho. 2004. Earthquake Disaster Mitigation for Urban Transportation Systems: An Integrated Methodology that Builds on the Kobe and Northridge Experiences. Modeling Spatial and Economic Impacts of Disasters, Y. Okuyama and S.E. Chang (eds.). Berlin: Springer-Verlag, 205-232.

Government Accountability Office. 2008. Approaches to Mitigate Freight Congestion. GAO-09163R. Washington, DC: United States Government Accountability Office. 
Government Accountability Office. 2011. Surface Freight Transportation: A Comparison of the Costs of Road, Rail, and Waterways Freight Shipments That Are Not Passed on to Consumers. GAO-11-134. Washington, DC: United States Government Accountability Office.

Ham, H., T.J. Kim, and D. Boyce. 2005. Assessment of Economic Impacts from Unexpected Events with an Interregional Commodity Flow and Multimodal Transportation Network Model. Transportation Research, Part A, 39(10): 849-860.

Ham, H., T.J. Kim, and D. Boyce. 2005. Implementation and Estimation of a Combined Model of Interregional, Multimodal Commodity Shipments and Transportation Network Flows. Transportation Research, Part B, 39(10): 65-79.

Harper. D. 2009. Fire controlled at Port of Catoosa fertilizer business. Tulsa World. Retrieved from

$<$ http://www.tulsaworld.com/article.aspx/Fire_controlled_at_Port_of_Catoosa_fertilizer_busines s/20090228_319_0_crewsw227541>

Isard, W., I.J. Azis, M.P. Drennan, R.E. Miller, S. Saltzman, and E. Thorbecke. 1998. Methods of Interregional and Regional Analysis. Brookfield, VT: Ashgate.

Kia, M. E. Shayan, and F. Ghotb. 2002. Investigation of Port Capacity under a New Approach by Computer Simulation. Computers and Industrial Engineering, 42(2-4): 533-540.

Koetse, M.J., and P. Rietveld. 2009. The Impact of Climate Change and Weather on Transport: An Overview of Empirical Findings. Transportation Research Part D, 14(3): 205-221.

Lave, L. B. 1995. Using Input-output Analysis to Estimate Economy-wide Discharges. Environmental Science and Technology, 29(9): 420A-426A.

Lee, T.-W., N.-K. Park, and D.-W. Lee. 2003. A Simulation Study for the Logistics Planning of a Container Terminal in View of SCM. Maritime Policy and Management, 30(3): 243-254.

Lee, B.K. and K.H. Kim. 2010. Optimizing the Block Size in Container Yards. Transportation Research Part E, 46(1): 120-135.

Leontief, W.W. 1966. Input-Output Economics. New York, NY: Oxford University Press.

Lian, C. and Y.Y. Haimes. 2006. Managing the Risk of Terrorism to Interdependent Infrastructure Systems Through the Dynamic Inoperability Input-Output Model. Systems Engineering, 9(3): 241-258.

MacKenzie, C., K. Barker, and F.H. Grant. 2012a. Evaluating the Consequences of an Inland Waterway Port Closure with a Dynamic Multiregional Interdependency Model. IEEE Transactions on Systems, Man, and Cybernetics Part A, 42(2): 359-370. 
MacKenzie, C., J.R. Santos, and K. Barker. 2012b. Measuring International Production Losses from a Disruption: Case Study of the Japanese Earthquake and Tsunami. International Journal of Production Economics, 138(2): 293-302.

MacKenzie, C.A. and K. Barker. 2013. Empirical Data and Regression Analysis for Estimation of Infrastructure Resilience, with Application to Electric Power Outages. Journal of Infrastructure Systems, 19(1): 25-35.

Martin Associates. 2001. An Assessment of the Impact of West Coast Container Operations and the Potential Impacts of an Interruption of Port Operations, 2000 (Lancaster, Pa.: Martin Associates, October 23, 2001), prepared for the Pacific Maritime Association.

Miller, R., and P. Blair. 2009. Input-Output Analysis. 2nd edition. Cambridge University Press.

National Cooperative Freight Research Program. 2010. Research Results Digest, Subject Areas: IV Operations and Safety, VII Rail, VIII Freight Transportation, IX Marine Transportation. $<$ http://onlinepubs.trb.org/onlinepubs/ncfrp/ncfrp_rrd_002.pdf $>$.

Office of Management and Budget (OMB). 2007. North American Industry Classification System, Washington, DC: National Technical Information Service.

Organization for Economic Co-Operation and Development. 2011. OECD.StatsExtrats. $<$ http://stats.oecd.org/Index.aspx $>$.

Orsi, M.J. and J.R. Santos. 2010. Incorporating Time-varying Perturbations into the Dynamic Inoperability Input-Output Model. IEEE Transactions on Systems, Man, and Cybernetics, Part A, 40(1): 100-106.

Pant, R., K. Barker, F.H. Grant, and T.L. Landers. 2011. Interdependent Impacts of Inoperability at Multi-modal Transportation Container Terminals. Transportation Research Part E: Logistics and Transportation, 47(5): 722-737.

Pant, R., K. Barker, and T.L. Landers. 2012. Analysis of Inland Waterway Disruptions on Interdependent Economic Systems. Proceedings of the 2012 Industrial and Systems Engineering Research Conference, G. Lim and J.W. Herrmann (eds.).

Rose, A. 2004. Defining and Measuring Economic Resilience in Disasters. Disaster Prevention and Management, 13(4): 307-314.

Sacone, S. and S. Siri. 2009. An Integrated Simulation-optimization Framework for the Operational Planning of Seaport Container Terminals. Mathematical and Computer Modelling of Dynamical Systems, 15(3): 275-293.

Santos, J.R. 2006. Inoperability Input-output Modeling of Disruptions to Interdependent Economic Systems. Systems Engineering, 9(1): 20-34. 
Santos, J.R., M.J. Orsi, and E.J. Bond. 2009. Pandemic Recovery Analysis using the Dynamic Inoperability Input-Output Model. Risk Analysis, 29(12): 1743-1758.

Simao, H.P. and W.B. Powell. 1992. Numerical Methods for Simulating Transient, Stochastic Queuing Networks - I: Methodology. Transportation Science, 26(4): 296-311.

Sohn, J., G.J.D. Hewings, T.J. Kim, J.S. Lee, and S.G. Jang. 2004. Analysis of Economic Impacts of an Earthquake on Transportation Network. Modeling Spatial and Economic Impacts of Disasters, Y. Okuyama and S.E. Chang (eds.). Berlin: Springer-Verlag, 233-256.

Talley, W.K., and V.Y.Lun. 2012. Port Security and the Quality of Port Interchange Service. The Blackwell Companion to Maritime Economics, 701-716.

Texas Transportation Institute, 2007. A Modal Comparison of Domestic Freight Transportation Effects on the General Public: Executive Summary.

Trbojevic, V.M., and B.J. Carr. 2000. Risk based methodology for safety improvements in ports. Journal of Hazardous Materials, 71(1): 467-480.

Tulsa Port of Catoosa. 2011. Interactive access to website. $<$ http://www.tulsaport.com>.

U.S. Army Corps of Engineers. 2010. Waterborne Commerce of the United States: Calendar Year 2009. New Orleans, LA: U.S. Army Corps of Engineers Waterborne Commerce Statistics Center.

U.S. Army Corps of Engineers. 2011. Interactive access of website.

$<$ http://www.iwr.usace.army.mil/ndc $>$.

U.S. Department of Transportation, Federal Highway Administration, 2008. Meeting Environmental Requirements after Bridge Collapse.

$<$ http://www.environment.fhwa.dot.gov/projdev/bridge_casestudy.asp\#ok>.

U.S. Department of Transportation. 2009. Freight Facts and Figures 2009. Federal Highway Administration, Office of Freight Management and Operations.

U.S. Department of Transportation. 2011. Maritime Administration America's Marine Highway. Report to Congress.

Yip, T. L. 2008. Port traffic risks-A study of accidents in Hong Kong waters. Transportation Research Part E: Logistics and Transportation Review, 44(5): 921-931. 


\section{APPENDIX}

Table A1. Sample Input-Output table matrix showing the balances between the supply outputs, intermediate demands, final demands and value added.

\begin{tabular}{|c|c|c|c|c|c|c|c|c|}
\hline \multirow{2}{*}{ Industry Supply } & \multicolumn{5}{|c|}{ Industry Demand } & \multirow{2}{*}{ Exports } & \multirow{2}{*}{$\begin{array}{c}\text { Other } \\
\text { demands }\end{array}$} & \multirow{2}{*}{ Demand I-O balance } \\
\hline & 1 & $\ldots$ & $j$ & $\ldots$ & $n$ & & & \\
\hline $\begin{array}{c}x_{1} \\
\vdots\end{array}$ & $\begin{array}{l}z_{11} \\
\vdots\end{array}$ & $\ldots$ & $\begin{array}{l}z_{1 j} \\
\vdots\end{array}$ & $\ldots$ & $\begin{array}{l}z_{1 n} \\
\vdots\end{array}$ & \multirow{6}{*}{$\begin{array}{c}e_{1} \\
\vdots \\
e_{i} \\
\vdots \\
e_{n}\end{array}$} & \multirow{6}{*}{$\begin{array}{c}d_{1} \\
\vdots \\
d_{i} \\
\vdots \\
d_{n}\end{array}$} & \multirow{6}{*}{$x_{i}=\sum_{j=1} z_{i j}+e_{i}+d_{i}$} \\
\hline$x_{i}$ & $z_{i 1}$ & $\ldots$ & $z_{i j}$ & $\ldots$ & $z_{i n}$ & & & \\
\hline$\vdots$ & $\vdots$ & & $\vdots$ & & $\vdots$ & & & \\
\hline$x_{n}$ & $z_{n 1}$ & $\ldots$ & $z_{n j}$ & $\ldots$ & $z_{n n}$ & & & \\
\hline Imports & $m_{1}$ & $\ldots$ & $m_{j}$ & $\ldots$ & $m_{n}$ & & & \\
\hline Other value added & $v_{1}$ & $\ldots$ & $v_{j}$ & $\ldots$ & $v_{n}$ & & & \\
\hline Supply I-O balance & & $\sum_{i=1}$ & & $u_{j}$ & & & & \\
\hline
\end{tabular}

Table A2. The 63 BEA industry and infrastructure sectors making up the illustrative examples.

\begin{tabular}{|c|c|c|c|}
\hline Industry & Description & Industry & Description \\
\hline 1 & Farms & 33 & Transit and ground passenger transportation \\
\hline 2 & $\begin{array}{l}\text { Forestry, fishing, and related } \\
\text { activities }\end{array}$ & 34 & Pipeline transportation \\
\hline 3 & Oil and gas extraction & 35 & Other transportation and support activities \\
\hline 4 & Mining, except oil and gas & 36 & Warehousing and storage \\
\hline 5 & Support activities for mining & 37 & Publishing industries (includes software) \\
\hline 6 & Utilities & 38 & Motion picture and sound recording industries \\
\hline 7 & Construction & 39 & Broadcasting and telecommunications \\
\hline 8 & $\begin{array}{l}\text { Food and beverage and tobacco } \\
\text { products }\end{array}$ & 40 & Information and data processing services \\
\hline 9 & $\begin{array}{l}\text { Textile mills and textile product } \\
\text { mills }\end{array}$ & 41 & $\begin{array}{l}\text { Federal Reserve banks, credit intermediation, and } \\
\text { related activities }\end{array}$ \\
\hline 10 & $\begin{array}{l}\text { Apparel and leather and allied } \\
\text { products }\end{array}$ & 42 & Securities, commodity contracts, and investments \\
\hline 11 & Wood products & 43 & Insurance carriers and related activities \\
\hline 12 & Paper products & 44 & Funds, trusts, and other financial vehicles \\
\hline 13 & $\begin{array}{l}\text { Printing and related support } \\
\text { activities }\end{array}$ & 45 & Real estate \\
\hline 14 & Petroleum and coal products & 46 & $\begin{array}{l}\text { Rental and leasing services and lessors of } \\
\text { intangible assets }\end{array}$ \\
\hline 15 & Chemical products & 47 & Legal services \\
\hline 16 & Plastics and rubber products & 48 & $\begin{array}{l}\text { Miscellaneous professional, scientific and technical } \\
\text { services }\end{array}$ \\
\hline 17 & Nonmetallic mineral products & 49 & Computer systems design and related services \\
\hline 18 & Primary metals & 50 & Management of companies and enterprises \\
\hline 19 & Fabricated metal products & 51 & Administrative and support services \\
\hline 20 & Machinery & 52 & Waste management and remediation services \\
\hline 21 & Computer and electronic products & 53 & Educational services \\
\hline 22 & $\begin{array}{l}\text { Electrical equipment, appliances, } \\
\text { and components }\end{array}$ & 54 & Ambulatory health care services \\
\hline
\end{tabular}




\begin{tabular}{l|lcl}
\hline 23 & Motor vehicles, bodies and trailers, & 55 & Hospitals and nursing and residential care facilities \\
24 & and parts & & \\
25 & Other transportation equipment & 56 & Social assistance \\
& Furniture and related products & 57 & $\begin{array}{l}\text { Performing arts, spectator sports, museums, and } \\
\text { related activities }\end{array}$ \\
26 & Miscellaneous manufacturing & 58 & Amusements, gambling, and recreation industries \\
28 & Wholesale trade & 59 & Accommodation \\
29 & Retail trade & 60 & Food services and drinking places \\
30 & Rir transportation & 61 & Other services, except government \\
31 & Water transportation & 62 & Federal government \\
32 & Truck transportation & 63 & State and Local Government \\
\hline
\end{tabular}

Table A3. Estimates of annual tonnage of exports and import through the Port of Catoosa for 2007.

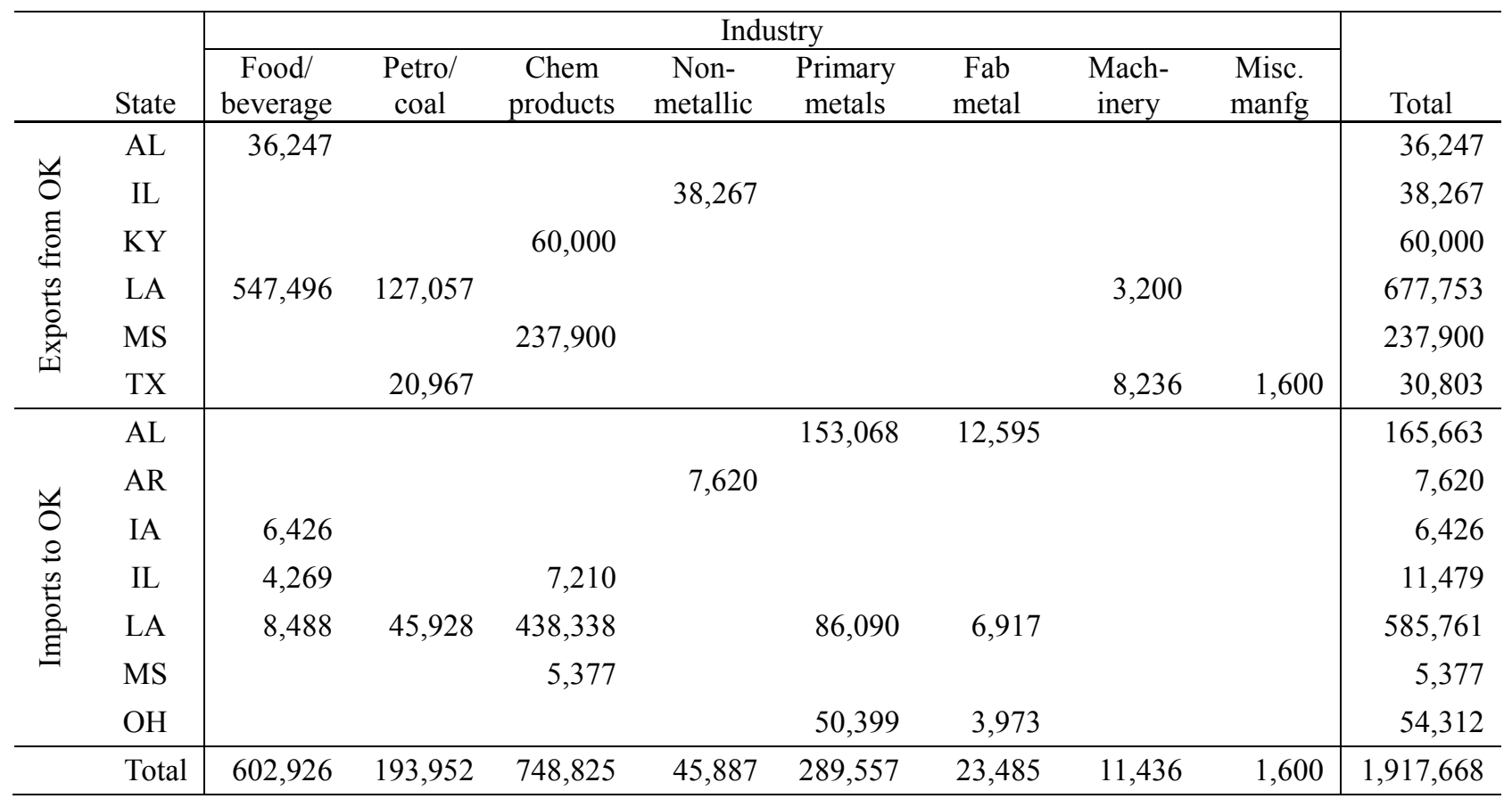

